\title{
Conditional deletion of $\beta 1$-Integrin in astroglia causes partial reactive gliosis
}

Abbreviated title: $\beta 1$-integrin deletion in astroglia

Stefanie Robel ${ }^{1,2}$, Tetsuji Mori ${ }^{2,3}$, Leda Dimou ${ }^{1}$, Inmaculada Rite ${ }^{1}$, Saida Zoubaa ${ }^{4}$, Jürgen Schlegel ${ }^{4}$, Swetlana Sirko ${ }^{5}$, Andreas Faissner ${ }^{5}$, Klaus-Armin Nave ${ }^{6}$, Reinhard Fässler ${ }^{7}$ and Magdalena Götz ${ }^{1,2,8 *}$

1Department of Physiological Genomics, Institute of Physiology, Ludwig-Maximilians University Munich, 80336 München, Germany; ${ }^{2}$ Institute for Stem Cell Research, HelmholtzZentrum München, 85764 Neuherberg, Germany; ${ }^{3}$ present address: Department of Anatomy and Cell Science, Kansai Medical University, 10-15 Fumizonocho, Moriguchi, Osaka 570-8506, Japan; ${ }^{4}$ Institute of Pathology, HelmholtzZentrum München, 85764 Neuherberg, Germany; ${ }^{5}$ Chair of Cell Morphology and Molecular Neurobiology, Ruhr-University-Bochum, 44780 Bochum, Germany; ${ }^{6}$ Department of Neurogenetics, Max-Planck-Institute of Experimental Medicine, 37075 Göttingen, Germany; ${ }^{7}$ Department of Molecular Medicine, MaxPlanck-Institute of Biochemistry, 82152 Martinsried, Germany; ${ }^{8}$ Munich Center for Integrated Protein Science, CiPS ${ }^{M}$

\section{*corresponding author:}

Magdalena Götz

Physiological Genomics

University of Munich (LMU)

80634 München 
Germany

Phone: +49-89-218075252

Fax: +49-89-218075216

magdalena.goetz@helmholtz-muenchen.de

Number of figures: 9

Number of tables: 0

Supplemental material: 6 Supplementary figures

Number of text pages: 41

Number of words: 11670

Number of words for Abstract: 221; for Introduction: 688; for Discussion: 2547

Keywords: astroglia, extracellular matrix, polarity

Acknowledgements: This work was supported by grants of the Deutsche Forschungsgemeinschaft, including the excellence cluster Center for Integrated Protein Science Munich, the European Community (Integrated Project EuTRACC, grant. no. LSHG-CT-2007-037445), the Bundesministerium für Bildung und Forschung, the Bavarian State Ministry of the Sciences, and Research and the Arts (M.G.). We thank Gwendolyn Behrendt for careful correction of this manuscript, Simone Bauer and Gabriele Jäger for excellent technical assistance and Susanne Schickle and Petra Peter for maintenance of the mouse colony. 


\begin{abstract}
Astrocytes play many pivotal roles in the adult brain, including the reaction to brain injury. Despite the well-known specialized contact of astroglial endfeet with the basement membrane surrounding blood vessels, still relatively little is known about signaling mediated at this interface. To approach these issues we deleted the $\beta 1$ integrin gene by different Cre lines such that the protein was reduced only at postnatal stages in both glia and neurons or specifically in neurons. Strikingly, only the former resulted in partial reactive gliosis, with all the hallmarks of reactive astrocytes comprising astrocyte hypertrophy and up-regulation of the intermediate filaments GFAP and vimentin, Tenascin-C and the DSD1 proteoglycan. In addition, we also observed some non-cell autonomous activation of microglial cells after conditional $\beta 1$-integrin deletion. However, neither reactive astrocytes nor microglia proliferated, suggesting that the loss of $\beta 1$-integrin-mediated signaling is not sufficient to elicit proliferation of these cells as observed after brain injury. As this partial reactive gliosis appeared in the absence of cell death and blood brain barrier disturbances, but did not appear after neuron-specific deletion of $\beta 1$-integrin, we conclude that $\beta 1$-integrin-mediated signaling in astrocytes is required to maintain them in a mature, non-reactive state and suggest alterations in $\beta 1$-integrin-mediated signaling as a key mechanism for eliciting reactive gliosis after injury.
\end{abstract}




\section{Introduction}

Astroglial cells are the most frequent cell type in the adult mammalian brain, performing multiple key functions (Kettenmann and Ransom, 2005; Araque, 2006). Together with microglia cells they mediate the reaction to injury, the 'reactive gliosis', with astrocytes changing their morphology and up-regulating intermediate filaments (GFAP, vimentin and nestin) and extracellular matrix (ECM) proteins, such as Tenascin-C and chondroitin sulfate proteoglycans (CSPG) (Mathewson and Berry, 1985; Pekny et al., 2007; Buffo et al., 2008). This astrocytic response is of crucial importance, as either inhibiting their reactive state (Okada et al., 2006; Herrmann et al., 2008) or killing them altogether (Bush et al., 1999) results in increased size of the lesion and reduced functional recovery. Thus, activation of astrogliosis is an essential part of successful wound healing. Moreover, we could recently demonstrate that a subset of reactive astrocytes dedifferentiates as far as assuming neural stem cell properties (Buffo et al., 2008), thereby providing a novel cell source for endogenous repair. However, besides these positive aspects of reactive gliosis, reactive astrocytes have also been implicated in negative effects by forming the glial scar constituting a barrier for axonal regeneration (Reier and Houle, 1988; Silver and Miller, 2004; Busch and Silver, 2007). Indeed, this prompts a profound interest in understanding the signals regulating reactive astrocytosis and in particular the upregulation of the Teanscins and Chondroitin-sulfate proteoglycans (ChSPGs), which contribute to the failure of axon regeneration (Morgenstern et al., 2002; Sandvig et al., 2004; Wanner et al., 2008). However, despite these important and divergent roles of astrocytes after injury, still relatively little is known about the molecular mechanisms of their activation. 
Cell death, mechanical impact, the rupture of the blood-brain barrier (BBB) and inflammation are major players in the process of reactive gliosis (for review see: (Ridet et al., 1997; Pekny and Nilsson, 2005), yet the molecular mechanisms mediating this response, especially its different aspects, are still only partially understood. While purinergic and other growth factor signaling pathways have been well studied in this context (Ridet et al., 1997; Okada et al., 2006; Gadea et al., 2008; Herrmann et al., 2008), particularly little is known about the precise effects of signals from the extracellular matrix (ECM) to glial cells after injury. ECM-mediated signaling is clearly of major importance in wound reactions in other systems like skin or kidney (Brakebusch et al., 2000; Kagami and Kondo, 2004; Tran et al., 2004), but ECM-glia signals have so far been difficult to study in the CNS in vivo.

Indeed, a possible role of ECM-mediated signaling to astrocytes is particularly relevant as astrocyte endfeet are in close contact to the basement membrane (BM) surrounding blood vessels in the intact, uninjured brain (Brightman, 1968; Brightman and Kaya, 2000; Sixt et al., 2001; Bragg et al., 2006). This contact is obviously interrupted after invasive injury, such as a trauma or stab wound injury, but it is not known to which extent the possible loss of BM-contact may contribute to the changes seen in reactive gliosis. The major receptors for BM proteins are members of the integrin family and dystroglycan, which is part of the dystrophin-associated glycoprotein complex (DGC) (del Zoppo and Milner, 2006). Interestingly, conditional deletion of dystroglycan resulted in GFAP up-regulation, suggesting a possible role of signaling via this complex in astroglia activation (Moore et al., 2002). However, dystroglycan was already lost at early developmental stages in these conditional knock-out mice, resulting in defects in neuronal migration and midline fusion as well 
as severe disruptions of the glia limitans (Moore et al., 2002), suggesting that either developmental aberrations or abnormal cell contacts to the subarachnoidal space may be involved in this phenotype. Notably, the DGC has been implicated in targeting the water channel aquaporin 4 (Aqp4) and the inward-directed potassium channel Kir4.1 to astroglial endfeet (Sievers et al., 1994a, 1994b; Bragg et al., 2006). These channels are redistributed after injury and may contribute to the glial reactivity, in particular the astrocyte swelling (landiev et al., 2006; Nesic et al., 2006; Ulbricht et al., 2008). Taken together, these data raise the suggestion that alterations in BMastrocyte signaling play a crucial role in the reaction to brain injury, but this has not been examined further.

In order to examine the role of ECM-mediated signaling to astrocytes, we focussed here on the role of $\beta 1$-integrin, as this subunit is part of most integrin receptors in the central nervous system (CNS) (Takada et al., 2007). Integrins are transmembrane receptors, which link the ECM to the intracellular actin cytoskeleton. They form heterodimers consisting of $\mathrm{a} \alpha$ and a $\beta$ subunit. Depending on their subunit composition, they bind different ligands in the ECM and perform distinct functions (Reichardt and Tomaselli, 1991; Brakebusch and Fassler, 2005; Takada et al., 2007). Conditional deletion of $\beta 1$-integrin during brain development led to defects in axonal guidance and synaptogenesis, as well as in glial differentiation and cell migration (Reichardt and Tomaselli, 1991; Graus-Porta et al., 2001; Blaess et al., 2004; Belvindrah et al., 2006; Huang et al., 2006; Belvindrah et al., 2007b). However, still virtually nothing is known about the role of $\beta 1$-integrin after later deletion in the postnatal brain. 


\section{Materials and Methods}

\section{Animals}

Mouse lines expressing the Cre-recombinase in different cell types, the hGFAP-Cre (Zhuo et al., 2001), and Nex-Cre mice (Goebbels et al., 2006) were maintained on a C57BL/6 background. Mice carrying $\beta 1$-integrin alleles flanked by loxP sites (Potocnik et al., 2000) were maintained on 129/SV background by mating homozygous females and males. Cre lines were then crossed with $\beta 1$-integrin-floxed mice to obtain $\beta 1$-integrin knockouts and control littermates.

All animal procedures were performed in accordance with the policies of the use of Animals and Humans in Neuroscience Research, revised and approved by the Society of Neuroscience and the state of Bavaria under licence number 55.2-1-54$2531-23 / 04$

\section{Immunohistochemistry}

Adult mice were transcardially perfused with $4 \%$ or $2 \%$ paraformaldehyde (PFA) in phosphate buffered saline (PBS) and brains were post-fixed in the same fixative for $2 \mathrm{~h}$ at $4^{\circ} \mathrm{C}$. Postnatal brains were removed and fixed by immersion in $4 \%$ PFA overnight. Fixed brains were cryoprotected in $30 \%$ sucrose in PBS at $4^{\circ} \mathrm{C}$ for cryosections. Frontal or sagittal sections were cut at 12 to $30 \mu \mathrm{m}$ thickness using a cryostat or $60 \mu \mathrm{m}$ using a vibratome and processed for immunohistochemistry as described previously (Hartfuss et al., 2001). The following antibodies were used in PBS containing 10\% normal goat serum and 0.5\% TritonX100: Anti-pan laminin (rat 1:1000, Chemicon); anti-laminin a1, a2, a4 or a5 (rabbit, 1:200, provided by Dr. 
Sasaki, Max-Plank-Institute of Biochemistry, Martinsried, Germany); anti-fibronectin (rabbit, 1:40, Chemicon); anti-pecam/ CD31 (rat, 1:100, BD Pharmingen) anti gliafibrillary acidic protein (GFAP; mouse IgG1, 1:1000, Sigma or rabbit, 1:1000, DAKO); anti-S100b (mouse IgG1, 1:1000, Sigma); anti-glutamine synthase (GS; mouse IgG2a, 1:250, DB Bioscience); anti- $\beta 1$ integrin (mouse IgG2a, 1:200, Chemicon); anti-Bromodeoxyuridine (BrdU, rat IgG2a, 1:200, Abcam or rat lgG2b, 1:200, Biozol); phospho-histone 3 (PH3, rabbit, 1:200, Upstate); anti-Ki67 (rat IgG2b, 1:50, DAKO); anti-Tenacin-C (rabbit, 1:200; provided by Andreas Faissner, University of Bochum, Germany); anti-CD11b (rat IgG2b, 1:250, Serotec); anti-glucose transporter (Glut)-1 (rabbit, 1:500, Chemicon); anti-collagen IV (rabbit, 1:80, Chemicon); anti-vimentin (goat, 1:20, Chemicon); anti-aquaporin4 (rabbit, 1:200, Chemicon); anti-dystrophin (rabbit, 1:5000, provided by Stefan Kröger, LMU Munich, Germany) anti- $\alpha$ dystrobrevin (rabbit, 1:100, provided by Stefan Kröger, LMU Munich, Germany); anti$\beta$-dystroglycan (mouse IgG2a, 1:200, Novocastra), anti-GSA-I-B4 (lectin-biotinyliert, 1:100, Sigma); anti-Iba1 (rabbit, 1:1000, Wako). Secondary antibodies were either conjugated to Alexa488 (1:500), Alexa594 (1:1000), Alexa633 (1:1000) from Molecular Probes or Cy3 (1:500), Cy5 (1:1000) from Dianova.

After mounting the stained sections in AquaPoly/Mount (Polysciences, Inc.), the analysis was performed at a confocal laser scanning microscope (Olympus, Fluoview; Zeiss LSM5) or an epifluorescent microscope (Zeiss, Axiophot; Olympus BX61).

5-bromo-2-deoxyuridine labeling of proliferating cells

In order to label proliferating cells $1 \mathrm{mg} / \mathrm{ml}$ 5-bromo-2-deoxyuridine (BrdU; Sigma) 
was administered to mice via the drinking water either for 14 consecutive days or, in order to label slow-dividing label-retaining cells, for 14 days followed by a 7 days chase (Kawaguchi et al., 2001).

\section{Analysis of cell death}

In order to examine cell death, we used the TUNEL staining kit (Roche) according to the instruction provided by the manufacturer, or an anti-activated Caspase 3 antibody (Promega, rabbit, 1:100).

\section{Western blot}

Brain tissue was dissected, lysed in lysis buffer (1\% NP-40, 0.5\% Na-deoxycholate, $0.1 \%$ SDS, $20 \mu \mathrm{g} / \mathrm{ml}$ aprotinin, $1 \mu \mathrm{g} / \mathrm{ml}$ leupeptin, $1 \mathrm{mM}$ PMSF, $1 \mathrm{mM} \mathrm{Na-O-vanadat),}$ and boiled at $95^{\circ} \mathrm{C}$ for 5 minutes after addition of $3 x$ loading buffer (20\% glycerol, $3 \%$ SDS, 10mM EDTA, $0.05 \%$ bromophenol blue). SDS-polyacrylamide gels (resolving gel: 8-10\%; stacking gel: 5\%) were run in SDS-PAGE running buffer. Proteins were transferred to PVDF membrane by semi dry blotting. Membranes were probed with rabbit $\beta 1$-integrin antibody (Wennerberg et al., 2000). For protein loading control, membranes were reprobed with anti-tubulin antibody (provided by Dr. Wehland, BGF, Braunschweig).

\section{Analysis of the blood brain barrier}

$200 \mu \mathrm{l}$ Evans blue solution (2\% in PBS) was administrated intraperitoneally and mice were killed after 1 hour. Brains were removed, immediately sliced and inspected for staining. Brains were then fixed by $4 \%$ PFA over night at $4^{\circ} \mathrm{C}$ on a rotary shaker. 
As Evans blue binds to proteins and may not allow to the detection of small disruptions of the blood brain barrier, we additionaly injected $165 \mathrm{mg} / \mathrm{kg}$ DextranFluorescein MW 3000 Da (Molecular Probes), or $5 \mathrm{ml} / \mathrm{kg}$ of $10 \%$ sodium fluorescein MW 376 Da intraperitoneally. After 20 minutes to 1 hour, mice were killed, brains were removed and frozen on dry ice. The frozen brains were cut at $12 \mu \mathrm{m}$ thickness using a cryostat and mounted on glass slides.

\section{Results}

Cell type specific deletion of $\beta 1$ - integrin in the central nervous system

In order to study the role of $\beta 1$-integrin in the adult CNS, we conditionally deleted $\beta 1$ integrin either only in neurons (by the use of a mouse line expressing Cre in the Nex-locus; (Goebbels et al., 2006) or relatively late in radial glial cells using the hGFAP-Cre mouse line, thereby affecting most glial cells and neurons (Zhuo et al., 2001; Malatesta et al., 2003). These Cre-mice were crossed with $\beta 1$-integrin-floxed animals that contain the entire coding and 3 ' noncoding sequence of the $\beta 1$-integrin gene flanked by loxP sites in order to ensure the loss of the entire $\beta 1$-integrin protein (Potocnik et al., 2000). In contrast, crossings with mice containing only exon2 of the $\beta 1$-integrin gene flanked by loxP site did not result in loss of $\beta 1$-integrin protein, or in the phenotype described below (data not shown).

Deletion of $\beta 1$-integrin by hGFAP-Cre

Previous work defined the onset of Cre-recombinase expression in the hGFAP-Cre mouse line at around embryonic day (E) 13 in the forebrain (Malatesta et al., 2003). 
Given the low transcriptional turnover and long persistence of the $\beta 1$-integrin protein after gene deletion (Brakebusch et al., 2000), we first examined the exact onset of $\beta 1$-integrin protein reduction in the cerebral cortex, the focus of our analysis. In agreement with the onset of Cre expression at E13 in this region, western blot analysis at this age revealed no reduction in $\beta 1$-integrin protein levels in the hGFAPCre,fl| $\mid 1 / \mathrm{fl} \beta 1$ mice (from now on referred to as $\beta 1-/-$ ) compared to control cortices (fl| $1 / \mathrm{fl} \mid \beta 1$ or hGFAP-Cre,fl $\beta 1 / \mathrm{WT}$ referred to as WT; Fig. 1A). Also 4 days after recombination, at E17, no decrease in $\beta 1$-integrin protein levels was yet detectable. In cortices of neonatal pups, however, reduced levels of $\beta 1$-integrin protein became apparent (Fig. 1B) and hardly any $\beta 1$-integrin protein was detectable one week later in the cortices of seven days old $\beta 1 / /$ - mice (Fig. 1C). Further consistent with the expression of Cre in radial glial cells of most CNS regions (Zhuo et al., 2001; Malatesta et al., 2003)(Malatesta et al., 2003), the $\beta 1$-integrin levels were also considerably reduced in other regions, like the basal ganglia, diencephalon, midbrain, hindbrain and spinal cord (Fig. 1C). However, relatively higher levels of remnant $\beta 1$ integrin protein remained detectable in the $\beta 1 / /$ midbrain (Fig. 1C), consistent with the previously reported weaker expression of Cre-recombinase in this region (Zhuo et al., 2001). In the spinal cord, Cre driven by the hGFAP promoter has a relatively late onset and is turned on in radial glial cells only at the end of neurogenesis (Barry and McDermott, 2005; Mori et al., 2005; McMahon and McDermott, 2007; Pinto et al., 2008). Consistent with a predominant recombination in glial cells, sparing most of the neurons, we observed also relatively higher $\beta 1$-integrin levels in the spinal cord of $\beta 1$-/- mice (Fig. 1C). 
Partial gliosis phenotype after loss of $\beta 1$-integrin in the forebrain

Consistent with previous results obtained by CNS-specific deletion of $\beta 1$-integrin (Graus-Porta et al., 2001; Blaess et al., 2004; Huang et al., 2006; Belvindrah et al., 2007a) $\beta 1-/$ - animals were viable into adult stages with a body weight similar to WT and no obvious differences in behavior compared to control littermates (data not shown). Moreover, the gross morphology of $\beta 1-/$ brains was indistinguishable from control littermates, with the exception of the cerebellum, which was smaller and contained fused folia in the $\beta 1$-integrin mutant mice (Supplementary Fig. $1 \mathrm{~A}, \mathrm{~B}$; see also (Graus-Porta et al., 2001; Blaess et al., 2004). We also noted a tendency of $\beta 1$ /- brains to be bigger than brains of control littermates (Supplementary Fig. 1A, B), possibly because of the phenotype described below. No neurons invading into layer 1 and beyond were detectable by Nissl or DAPI staining in $\beta 1-/$ - cortices (data not shown) in contrast to previous results obtained by deleting $\beta 1$-integrin with earlier onset Cre lines (Nestin-Cre or Emx1-Cre; (Graus-Porta et al., 2001; Huang et al., 2006). Furthermore, neurons appeared normal in numbers, morphology and transmitter identity in the $\beta 1$-/- cortices (data not shown and Suppl. Fig. 1C, D). Also myelination degree and mature oligodendrocyte numbers (as judged by proteolipid protein, myelin-associated glycoprotein and CC1-immunoreactivity) appeared grossly normal in the mutant cortex (data not shown and Suppl. Fig. 1E-H).

However, we noted massive alterations in astroglial cells with a pronounced upregulation of GFAP (Fig. 2A, C) and a hypertrophic morphology with enlarged cell somata and thickened processes of GFAP- or S100ß- or glutamine synthase (GS)immunoreactive astrocytes in $\beta 1$-/- cortices (Fig. 2D, D'). GFAP-immunoreactivity is normally restricted to white matter (WM) and subpial astrocytes in WT cortex (Fig. 
2A, C, E-K) and only few $\mathrm{GFAP}^{+}$cells are located in the cortical Gray Matter (GM, $13.2 \pm 23.8 \mathrm{GFAP}^{+}$cells $/ \mathrm{mm}^{2}$ and Fig. $\left.2 \mathrm{~A}, \mathrm{E}, \mathrm{E}\right)$.). In pronounced contrast, many $\mathrm{GFAP}^{+}$cells were found to be scattered throughout the entire $\beta 1-/$ - telencephalon and cortical parenchyma including the GM $\left(383 \pm 4.5 \mathrm{GFAP}+\right.$ cells $/ \mathrm{mm}^{2}$, Fig. $2 \mathrm{C}, \mathrm{F}$, $\left.F^{\prime}\right)$ and co-localization with $S 100 \beta$ revealed that virtually all astrocytes in the mutant cortex now co-expressed GFAP (data not shown). As astrocytes that become reactive are known to up-regulate various proteins present exclusively in immature glial cells (Pekny et al., 2007; Buffo et al., 2008), such as the intermediate filament vimentin or the ECM proteins Tenascin-C and chondroitin sulfate proteoglycans (Joester and Faissner, 2001; Busch and Silver, 2007), including the DSD-1 epitope recognized by the 473HD antibody (Garwood et al., 2001), we next examined whether these proteins were also increased in the $\beta 1-/$ - cortices. Indeed, many vimentin-immunoreactive hypertrophic astrocytes were present in the mutant cortex, whereas staining was detectable exclusively in the subependymal zone (SEZ) of WT brains (Fig. 2E-F" and data not shown). Strikingly, immunoreactivity for Tenascin-C and the DSD-1 epitope was also strongly increased throughout the $\beta 1-/$ - cortex (Fig. $\left.2 \mathrm{G}-\mathrm{K}^{\prime \prime}\right)$. Thus, most of the proteins up-regulated in reactive astrocytes after injury are also up-regulated in $\beta 1 /-$ astrocytes.

A further hallmark of reactive gliosis is that many reactive astrocytes re-enter the cell cycle and proliferate (Buffo et al., 2005; Buffo et al., 2008). To monitor cell proliferation, the DNA-base analogon 5-bromo-2-deoxyuridine (BrdU) was provided for 14 days in the drinking water to label all cells undergoing S-phase during this period, including very slowly dividing cells. BrdU-positive cells were detected in the regions of adult neurogenesis, the subependymal zone (SEZ) and subgranular zone 
of the hippocampus (SGZ) in apparently similar numbers in control and $\beta 1-/-$ mice (data not shown). BrdU-labeled cells were also scattered throughout the brain parenchyma in both WT and $\beta 1 /$ cortices and their number was also well comparable between the genotypes $\left(131.1 \pm 21.5 \mathrm{BrdU}+\mathrm{mm}^{2}\right.$ in $\mathrm{WT}, \mathrm{n}=4 ; 147.4 \pm$ 53.4 $\mathrm{BrdU}+/ \mathrm{mm}^{2}$ in $\beta 1-/-, \mathrm{n}=7$ ). In intact, not injured cortices, these dividing, BrdUincorporating cells in the gray matter (GM) are adult progenitors that are mainly Olig2-positive (Buffo et al., 2005; Dimou et al., 2008) and generate mostly NG2 glia (Buffo et al., 2005; Dimou et al., 2008). Virtually none of these BrdU-incorporating progenitors contains antigens characteristic for astrocytes (Buffo et al., 2008; Dimou et al., 2008). Consistent with these previous data, we rarely detected BrdU-positive cells co-localizing with GFAP $\left(0.2 \pm 0.7 \mathrm{BrdU}^{+\mathrm{GFAP}^{+}} / \mathrm{GFAP}^{+}\right.$cells) or $\mathrm{S} 100 \beta$ (data not shown) in the GM of control cortices and a comparable low proportion of $\mathrm{BrdU}^{+}$ cells co-localized with GFAP also in the $\beta 1-/$ - cortices $\left(3 \pm 1.8 \mathrm{BrdU}^{+} \mathrm{GFAP}^{+} / \mathrm{GFAP}^{+}\right.$ cells). Thus, most of the reactive astrocytes seen after $\beta 1$-integrin deletion do not proliferate, whereas virtually half of the entire population of reactive astrocytes resumes proliferation after stab wound injury (Buffo et al., 2008). Indeed, also the total number of $S 100 \beta$-immunoreactive astrocytes was similar in WT and $\beta 1-/$ cortices (418.7 $\pm 19.2 \mathrm{~S} 100 \mathrm{~b}^{+} / \mathrm{mm}^{2}$ in WT; $381.6 \pm 27 \mathrm{~S} 100 \mathrm{~b}^{+} / \mathrm{mm}^{2}$ in $\left.\beta 1-/-; \mathrm{n}=4\right)$. Taken together, deletion of $\beta 1$-integrin by hGFAP-Cre results in a partial gliosis with hypertrophic astrocytes that up-regulate GFAP, vimentin, Tenascin-C and DSD1, but fail to proliferate.

Consistent with the $\beta 1$-integrin reduction throughout the CNS, the partial reactive gliosis phenotype was also observed in other CNS regions, including the diencephalon (Suppl. Fig. 2C, D), cerebellum and hindbrain (Suppl. Fig. 2G-K). 
Interestingly, no GFAP-positive astrocytes were observed in the midbrain of the $\beta 1-/$ mice (Suppl. Fig. 2E, F) consistent with the lower degree of recombination observed here (Fig. 1C) and reported previously (Zhuo et al., 2001). Of particular interest in this regard is the spinal cord, as the late onset of hGFAP-Cre-mediated recombination largely hits glial cells in this region, and spares the earlier progeny of radial glial cells, the neurons (Mori et al., 2005; Pinto and Götz, 2008). Interestingly, we also observed a profound gliosis in the spinal cord of $\beta 1-/$ - mice (Suppl. Fig. 3B, B', D), while little to no GFAP-immunoreactivity was observed in the GM of WT spinal cord littermates (Suppl. Fig. 3A, A'). This phenotype in the spinal cord hence implies that loss of $\beta 1$ integrin in glial cells is sufficient to elicit this response.

\section{Deletion of $\beta$ 1-integrin by Nex::Cre}

To further elucidate in which cell types the loss of $\beta 1$-integrin protein has to occur to elicit this phenotype, we used Nex::Cre mice to delete $\beta 1$-integrin at around E11.5 exclusively in intermediate progenitors and neurons (Beggs et al., 2003; Blaess et al., 2004; Wu et al., 2005; Goebbels et al., 2006). The bHLH transcription factor Nex belongs to the NeuroD family and is expressed in most neocortical and hippocampal pyramidal neurons and their immediate progenitors, but not in non-neuronal cells (Schwab et al., 1998; Wu et al., 2005; Belvindrah et al., 2007a). However, even in 6 months old mice, no gliosis phenotype could be observed in the CNS of Nex::Cre, $f \beta 1 / f \beta 1$ (Fig. $3 A, B$ ), suggesting that the loss of $\beta 1$ integrin in neurons is not involved in eliciting the gliosis phenotype. Indeed, $\beta 1$-integrin was successfully deleted in these mice from on early stages, as they exhibited pronounced defects in myelination (data not shown). These data therefore indicate that deletion of $\beta 1$ - 
integrin in cortical neurons has severe effects on the interaction with myelinating oligodendrocytes, but does not affect astrocyte polarity and reactivity.

Partial gliosis after hGFAP-Cre mediated $\beta 1$-integrin deletion is not due to cell death In order to understand the mechanisms causing the reactive gliosis phenotype after GFAP-Cre-mediated deletion of $\beta 1$-integrin we next examined cell death as a possible cause. Integrins have been implicated in the regulation of cell survival (Stupack, 2005) and cell death occurring after brain injury is one of the stimuli potentially eliciting reactive gliosis (for review see: ). We therefore tested for necrosis by cresyl violet (Nissl)- (Suppl. Fig. 4A-B'), DAPI-staining (data not shown) and apoptosis by staining for activated caspase 3 (Suppl. Fig. 4C-D') and by a terminal desoxynucleotidyl transferase (TUNEL) assay (data not shown) after deletion of $\beta 1$ integrin. Comparable to the very low number of pyknotic or activated caspase 3positive nuclei in WT cortices, we observed hardly any dying cells in the $\beta 1-/-$ cortices at a time when the partial reactive gliosis phenotype was already very pronounced (two months old mice). These data suggest that $\beta 1$-integrin-deficient cells including the reactive astrocytes themselves and neurons survive well in the adult brain.

Microglia activation is part of the reactive gliosis after loss of $\beta 1$-integrin Normally, after brain damage, not only astrocytes but also microglia react and become activated (Hanisch and Kettenmann, 2007), prompting us to examine their status and number in $\beta 1 /$ - animals. Overall, we found an almost comparable immunostaining for the microglia-specific antigen lba1 in WT and mutant brains (Fig. 
3A, B). However, at closer inspection we noted a slight increase in immunoreactivity accompanied with a relatively higher number of immuno-labeled processes visible in $\beta 1-/-$ cortices (Fig. 3B, B'). Moreover, some Iba1+ cells in the mutant seem to be activated as they possess hypertrophic processes (Fig. 3B' red arrows). To further examine whether or not these microglia cells are indeed activated, we used a second marker, GSA-I-B4, to specifically label activated microglia (Chang et al., 2003). Consistent with the lack of microglia activation in WT control brains, we only observed endothelial cells immunopositive for GSA-I-B4 in the WT (Fig. 3A, A") as described previously (Tuori et al., 1994). However, in addition to endothelial cells some GSA-positive microglia cells were visible in $\beta 1-/$ - brains, especially in the upper cortical layers (Fig. 3B, B"). Nevertheless the number of activated GSA ${ }^{+}$ microglia in the $\beta 1-/$ - cortex was much smaller than after stab wound injury (Figure 3C-C") .

After injury, activated microglia migrate towards the injury site and resume proliferation to increase their cell number at the site of injury. Indeed, quantification of the number of $\mathrm{Iba} 1^{+}$microglial cells in layers I to III revealed a statistical significant increase in number in mutant brains $\left(536.1 \pm 41.5 \mathrm{lba} 1^{+} / \mathrm{mm}^{2}\right.$ in WT; $654.5 \pm 30.7 \mathrm{lba} 1^{+} / \mathrm{mm}^{2}$ in $\beta 1-/-; \mathrm{n}=3$ ). To examine whether proliferation contributes to this increase in microglia number in the mutant cortices, we used the same BrdU application as described above (BrdU addition to the drinking water for 2 weeks). Similar to the astrocytes, only few microglial cells were dividing in WT as well as $\beta 1$ /- cortices (1.8 $\pm 0.4 \mathrm{lba}^{+} \mathrm{BrdU}^{+} / \mathrm{lba}^{+}$in WT; $3.5 \pm 3.5$ in $\left.\beta 1-/-\right)$, consistent with the lack of a proliferative response of microglial cells. We conclude therefore that microglia are only partially activated after deletion of $\beta 1$-integrin without showing an 
increase in proliferation.

Microglia cells are of mesodermal origin and should not be affected by the hGFAPCre-mediated recombination, suggesting that their activation may rather be due to non-cell-autonomous mechanisms. To directly exclude a possible recombination in microglia, we used reporter mice (Z/EG, (Novak et al., 2000) indicating recombination by GFP-expression. Indeed, double-staining for GFP and lba1 revealed no double-positive cells $(n=423)$ in mice with recombination mediated by hGFAP-Cre (Suppl. Fig?), supporting our previous data that recombination in these mice affects neurons, astrocytes and oligodendrocytes (Malatesta et al., 2003).

\section{No blood brain barrier disruption after deletion of $\beta 1$-integrin}

Microglia activation is often elicited by disruption of the blood brain barrier (BBB) that also occurs after various brain injuries ((Pekny and Nilsson, 2005). We therefore examined whether disruption of the BBB may occur after deletion of $\beta 1$-integrin and contribute to elicit the partial reactive gliosis phenotype. Towards this end, we injected tracer substances of distinct size intraperitoneally and examined their presence in the brain vessels and parenchyma 20 minutes after injection. If the BBB would be leaky, these substances should enter the brain parenchyma, whereas an intact BBB would restrict their passage to the lumen of the blood vessels. Evans Blue was used to follow larger size molecules as it binds to albumin forming a high molecular weight complex (MW $68.500 \mathrm{Da}$ ). We also injected dextran-fluorescein with the molecular weight of $3000 \mathrm{Da}$ and sodium fluorescein, one of the smallest tracers (MW $376 \mathrm{Da}$ ) to detect BBB disruption (Kozler and Pokorny, 2003). Although all the tracers were detected in the blood vessel lumen indicating that they reach the 
brain vessels (Fig. 4A, B), neither Evans Blue nor any of the fluoresceins were leaking into the brain parenchyma of WT or $\beta 1$-/- mice (data not shown and Fig. 4AC). This is in pronounced contrast to the prominent distribution of both Evans Blue and fluorescein in the cortex parenchyma after stab wound injury (Fig. 4D). We therefore conclude that the tracer injections are reliable and can reveal BBB disruption if it occurs. As no such disruptions were detectable in the $\beta 1 /-$ brains we further conclude that the BBB is indeed functionally intact despite the absence of $\beta 1$ integrin in most brain cells including the astrocyte endfeet lining the blood vessels. Thus, these experiments suggest that the partial reactive gliosis phenotype observed in the conditional $\beta 1$-integrin mutant cortex is not secondary to any of the above tested events (cell death or BBB leakage).

\section{Basement membrane integrity after $\beta 1$-integrin deletion}

As $\beta 1$-integrin has been shown to be required in cells making contact to the BM (e.g. endothelial cells and radial glia) for maintenance of BM integrity (Graus-Porta et al., 2001; Brakebusch and Fassler, 2005; Belvindrah et al., 2006), we examined whether the $\mathrm{BM}$ is still intact in the $\beta 1 / /-$ cortex. CollagenIV, perlecan and laminin are the three major components of the BM and immunostaining for all three proteins nicely outlined the cortical blood vessels and glia limitans at the pial interface in two months old WT and $\beta 1-/$ - mice (Fig. 5A-C'). A similar staining was also observed for fibronectin (Fig. 5D) further supporting the integrity of the BM at least at the light microscopic level. This is profoundly different from mice with either earlier deletion of B1-integrin (Graus-Porta et al., 2001) or the hGFAP-Cre mediated deletion of dystroglycan that exhibited severe disruptions of the glia limitans (Moore et al., 
2002). However, in older animals (six months of age) we observed disruptions in CollagenIV-immunoreactivity along the larger blood vessels, and the staining sometimes appeared punctuate (Fig. 5E, E'). The smaller capillaries, however, seemed still to be intact (data not shown and see below). Blood vessels near the pial surface seemed to be more strongly affected. Notably, these alterations were also observed at the leptomeningeal BM at the pial surface of the $\beta 1-/$ - cortex (data not shown and see below).

These observations prompted us to examine the BM at the ultrastructural level in WT and mutant littermates at two and six months of age. Consistent with our observations at the light microscopic level, we only observed defects in the BM at later stages. For example, the zipper-like structure of the leptomeningeal BM was disrupted only in the $\beta 1-/$ - cortices (visible as bright spots separating the two BM sheaths) but never in WT samples (Fig. 6A, B). In contrast, the perivascular BM of capillaries seemed to be still intact at the ultrastructural level even in six months old B1-/- mice (Fig. 6A', A", B', B"). Glial endfeet frequently appeared swollen in both genotypes, possibly because of the fixation, but otherwise appeared normal and were closely attached to the BM surrounding intracerebral capillaries in two (data not shown) and six month old mice (Fig. 6A, B). Taken together, these data allow two important conclusions. First, the partial reactive gliosis phenotype is neither correlated to nor resulting from defects in the BM. Second, defects in the BM can be observed preferentially at the pial surface only some while after loss of $\beta 1$-integrin protein, indicating that $\beta 1$-integrin is less important for BM maintenance in postnatal glia compared to radial glia cells (Graus-Porta et al., 2001; Moore et al., 2002). 


\section{Defects in astrocyte endfeet after deletion of $\beta 1$-integrin}

Given the negative evidence for any indirect effect, like cell death, BBB and BM disruption, possibly causing the reactive gliosis in these mice, we searched for a phenotype within the astrocytes that may initially cause this phenotype. As various proteins, like Aqp4 and components of the DGC, are localized to the astrocyte endfeet, alterations at this interface may occur after $\beta 1$-integrin deletion. Therefore, we examined the localization of these proteins. Consistent with previous studies (Moore et al., 2002; Bragg et al., 2006; Milner et al., 2008), immunostainings for both Aqp4 and DGC proteins (dystrophin-, $\alpha$-dystrobrevin- and $\beta$-dystroglycan) continuously outlined blood vessels in the WT cortex (Fig. 7A, A', C, C', E, E' and data not shown). In contrast, in both two or six months old $\beta 1-/$ - cortices, staining for all these components was often punctate and appeared disrupted along some vessels (Fig. 7B, B',D, D', F, F'). These data suggest that $\beta 1$-integrin deficient astrocytes are not capable of sustaining their polarized protein localization to their endfeet structures, even though their processes are still in close contact to the BM. The defects in protein targeting to astroglial endfeet raised the question whether BM components synthesized by astrocytes may still be delivered normally. This can be examined at larger blood vessels that possess two BMs, the inner one that is synthesized by endothelial cells and the outer one that is produced by astroglial endfeet (Brightman, 1968; Sixt et al., 2001). Endothelial cells and astrocytes express different isoforms of laminin. The $\alpha 4$ and $a 5$ laminin isoforms are synthesized by the endothelial cells, whereas the $\alpha 1 \square$ and $\alpha 2$ chains are produced by astrocytes (Sixt et al., 2001). Specific immuno-staining for the endothelial cell-derived laminins (a4 and a5) showed smooth and continuous signal nicely outlining brain vessels in both, 
WT and $\beta 1-/$ - cortices (Fig. 8E-H). In contrast, the staining pattern of the astrocytic $\alpha 1$ and $\alpha 2$ laminin chains was severely disrupted and patchy in the $\beta 1-/$ - cortices, but not in WT littermates (Fig. 8A-D). These data demonstrate defects in the proper location of astrocyte derived laminin chains, consistent with other defects in astrocyte endfeet observed after $\beta 1$-integrin deletion.

\section{Developmental appearance of gliosis phenotype}

In order to understand how the loss of $\beta 1$-integrin may cause the defects in astrocyte polarity and reactivity, we examined the onset of gliosis and disturbances in astroglial endfeet or laminin secretion. Notably, irregularities in $\alpha 1$ and a2 lamininimmunoreactivity were already visible at the end of the first postnatal week in $\beta 1-/-$ mice (Suppl. Fig. 5I-M), a few days after reduced levels of $\beta 1$-integrin protein were detectable. However, no overall BM disruptions were seen at this stage in the $\beta 1-/-$ mice (data not shown). With only a slight delay, hypertrophy and excessive GFAPimmunoreactivity could be detected in astrocytes of the $\beta 1 /$ - cortices (Suppl. Fig. $5 \mathrm{~N}-\mathrm{Q})$. During astrocyte development, GFAP is transiently up-regulated also in the WT cortex during the first postnatal weeks with highest levels around the end of the second postnatal week (Suppl. Fig. 5G, N). Thereafter, GFAP protein declines and is maintained only in a small subset of GM astrocytes underneath the pial surface (Suppl. Fig. 5P), whereas fibrous astrocytes residing in the WM remain GFAPimmunoreactive. In $\beta 1$-/- cortices GFAP-immunoreactivity appeared at the same time as in WT and the size of GFAP-positive astrocytes was still comparable within the first postnatal week (Suppl. Fig. 5B, H). However, by the end of the second postnatal week, clearly hypertrophic GFAP-immunoreactive cell bodies with thick processes 
became detectable in the $\beta 1$-/- cortices (Suppl. Fig. 5O, Q). By examining GFAPimmunoreactivity, astroglial cell body size and laminin $\alpha 1$ and $\alpha 2$-immunostainings we noted that the phenotype apparently started from the pial surface and then progressed towards the deeper cortical layers. At the third postnatal week, hypertrophic GFAP+ astrocytes were present throughout the brain parenchyma in the cortex and other brain regions (Suppl. Fig. 5Q, Suppl. Fig. 6). Taken together, these results suggest that the lack of $\beta 1$-integrin in astrocytes interfered with their proper polarization and normal development causing a gliosis phenotype already within the first postnatal weeks (see also (Graus-Porta et al., 2001; Belvindrah et al., 2007a; Belvindrah et al., 2007b).

\section{Discussion}

Whereas the role of $\beta 1$ integrin in radial glial cells during development has been well examined (Georges-Labouesse et al., 1998; Beggs et al., 2003; Herms et al., 2004; Haubst et al., 2006; Belvindrah et al., 2007a; Schroder et al., 2007), still very little was so far known about the interaction between astrocytes and the leptomeningeal and vascular BMs in the postnatal and adult brain.

Here we succeeded to study the postnatal role of $\beta 1$-integrin by the use of hGFAPdriven Cre recombinase. Whereas recombination in the cortex starts around E13 in this mouse line (Malatesta et al., 2003) and most proteins have disappeared within few days after recombination (Moore et al., 2002; Cappello et al., 2006), stability of the integrin proteins resulted in persistence of $\beta 1$-integrin for about one week after 
recombination. Indeed, the phenotypes observed after earlier deletion of $\beta 1$-integrin by the use of earlier onset Cre lines like the disruption of the glia limitans and BM at the pial surface and neuronal ectopias mostly in cortical layer I were not observed after deletion with hGFAP-Cre as described here. The absence of developmental malformations therefore allowed us to clarify the role of $\beta 1$-integrin in the postnatal brain and elucidate the etiology and nature of the major phenotype elicited at this later stage, namely the partial reactive gliosis. Notably, GFAP up-regulation has been described in previous reports after early deletion of $\beta 1$-integrin (Belvindrah et al., 2007a), focal adhesion kinase (Beggs et al., 2003) or cdc42 (Cappello et al., 2006), but this phenotype had neither been examined more closely nor was its cause identifiable given the profound developmental aberrations.

\section{$\beta 1$-integrin functions in astroglial cells}

Here we could show that this reactive gliosis phenotype is due to an important role of b1 integrin in postnatal astroglial cells. First, the gliosis phenotype occurred within the first postnatal weeks at a time when abnormalities were only observed in astrocytes and their secreted BM components. Moreover, genetic evidence using different Cre-lines, such as the Nex::Cre line, demonstrated clearly that deletion of $\beta 1$ integrin only in neurons does not elicit such a reactive gliosis phenotype. The onset of Cre expression in the Nex locus occurs at very early stages in neurons as soon as they are born (Wu et al., 2005; Goebbels et al., 2006) in contrast to previous neuron-specific deletion of $\beta 1$-integrin by CAMKinase-Cre where only mature pyramidal neurons at postnatal stages were affected (Huang et al., 2006). After hGFAP-Cre-mediated $\beta 1$-integrin deletion, we observed no obvious defects in 
oligodendrocytes consistent with data obtained by oligodendrocyte specific $\beta 1$ integrin deletion (CNP::Cre; (Benninger et al., 2006). Based on these results and the absence of gliosis in mice with Nex::Cre mediated $\beta 1$ integrin deletion, that had severe myelination defects, we conclude that gliosis is unlikely to be influenced by the presence or absence of $\beta 1$-integrin in oligodendrocytes and neurons. Thus, $\beta 1$ integrin mediated signaling is required within astrocytes to maintain these cells in a mature, non-reactive state. Interestingly, glial reactivity was not restricted to astrocytes, but also included a partial activation of microglial cells. However, hGFAPCre-mediated recombination does not occur in microglial cells, indicating that noncell-autonomous aspects account for this activation. These data therefore suggest an intriguing link between astrocyte reactivity and microglia activation and raise new questions in regard to the communication between astrocytes and microglia.

\section{$\beta 1$ - integrin in reactive gliosis}

Notably, the effect that loss of $\beta 1$-integrin in astrocytes exerted on their activation is rather comprehensive, recapitulating most aspects of reactive gliosis, except the reversion to a proliferative progenitor/stem cell state (Buffo et al., 2008). Given the multitude of changes after acute or chronic injury (Ridet et al., 1997; Pekny and Nilsson, 2005), it is striking to see that removal of a single protein, $\beta 1$-integrin, is sufficient to elicit all these changes with astrocytes not only up-regulating GFAP and vimentin, but also Tenascin-C and the chondroitin sulfate proteoglycan DSD1, as well as becoming hypertrophic and losing their endfeet polarity including the directed secretion of $\alpha 1$ and $\alpha 2$ laminin. Interestingly, virtually all of the changes characteristic for reactive astrocytes occur rather fast after loss of $\beta 1$-integrin protein. 
This implies $\beta 1$-integrin mediated signaling as the key pathway maintaining astrocytes in a normal, mature and non-reactive state. Indeed, integrin expression is rapidly down-regulated by endothelial and astroglial cells after focal cerebral ischemia (Wagner et al., 1997). Also $\beta 1$-integrin ligands, such as laminin, collagenIV, fibronectin and perlecan are down-regulated after injury (del Zoppo and Milner, 2006), suggesting that these alterations result in changes at the contact of astrocyte endfeet to the BM, besides the direct BM severance after injury. Taken together, these data imply alterations at the astrocyte-BM interface as one of the first and key steps in astroglial reactivity to injury.

Deletion of $\beta 1$-integrin in astrocytes leads to polarity defects

Careful analysis of the gliosis phenotype after $\beta 1$-integrin deletion revealed the alterations in astrocyte polarity as one of the earliest phenotypes in these mice, suggesting that further changes may well be downstream of these initial alterations in integrin-mediated signaling at the astrocyte endfeet-BM interface. Already within the first two postnatal weeks, the targeted deposition of laminin $\alpha 1$ and $\alpha 2$ from astroglial cells is affected, suggesting early aberrations at the astroglia-BM interface. Conversely, the $\alpha 4$ and $\alpha 5$ laminin isoforms derived from endothelial cells are still normally deposited. Notably, astrocytes and endothelial cells not only produce different types of laminins, but also exhibit a distinct laminin receptor composition: endothelial cells express mainly the integrin receptor $\alpha 6 \beta 4$ binding to laminin $\alpha 5$, whereas astrocytes additionally have $\alpha 1 \beta 1$, a receptor for laminin $\alpha 1$ (Wagner et al., 1997). Missing the latter receptor in mutant animals could possibly account for the disrupted staining pattern of the correlated ligand, or, targeted secretion at this 
interface may fail because of early defects in astrocyte polarity. Indeed, we also detected defects in the localization of proteins of the dystrophin-associated glycoprotein complex as well as Aqp4 to the astrocyte endfeet. Interestingly, aquaporins are involved in water balance and the reduction of Aqp4 has been implicated in mediating cell swelling and hypertrophy after injury (Verkman et al., 2006; Saadoun et al., 2008). Moreover, the ECM receptor dystroglycan has been shown to be necessary for proper targeting of Aqp4 to the endfeet of astroglia (Bragg et al., 2006). Thus, initial disturbances in astrocyte polarity as indicated by defects in targeting or maintenance of DGC at the endfeet-BM junction, may then lead to further defects at this interface illustrated by the partial disruptions of Aqp4 location. These accumulating defects at the astrocyte-BM interface may ultimately result in the phenotype of partial reactive gliosis comprising astrocyte hypertrophy and up-regulation of GFAP, vimentin, TN-C etc.

Basement membrane defects occur only secondary to reactive gliosis phenotype In this regard it is important to consider that the BM is only affected several months after loss of $\beta 1$-integrin. Both at the ultrastructural level, as well as monitored by pan-laminin, fibronectin or collagenIV immunostaining no aberrations in localization and expression could be observed for several months after birth, despite the virtual loss of $\beta 1$-integrin within the first two postnatal weeks. This is the case despite the alterations seen very early in the deposition of the laminin isoforms produced by astrocytes, the $\alpha 1$ and $\alpha 2$ laminin chains, implying that their partial lack did not affect the overall structure and maintenance of the BM. Moreover, the presence of all other main BM components, such as fibronectin, other laminins and collagenIV in normal 
amounts allows the conclusion that the aberrant DGC location is not resulting from the lack of ligand binding for this complex.

The lack of an early BM phenotype in mice with hGFAP-Cre-mediated deletion of $\beta 1$ integrin as observed after earlier interference with either $\beta 1$-integrin itself, or downstream signaling components such as FAK (Beggs et al., 2003), or dystroglycan (Moore et al., 2002), highlights the different importance of the signaling complex at the glial endfeet during development in radial glial cells and at postnatal stages in astrocytes. Although impairment of either integrin-mediated or DGC-mediated signaling already in radial glial cells results in disruptions of the leptomeningeal BM within few days, such failures seemingly take much longer and never reach such a severity when $\beta 1$-integrin protein is only deleted at postnatal stages. Finally, these data also support our conclusion that alterations in the BM are not the cause for the partial reactive gliosis phenotype, but rather develop secondary to the alterations in astroglial polarity.

\section{The BBB is not affected by loss of $\beta 1$-integrin from astrocytes at postnatal stages}

Astrocytic endfeet are in close proximity to the plasma membrane of endothelial cells and are separated only by the BM. As the astroglial perivascular sheet is a unique feature of CNS capillaries and forms at around the same time as the permeability barrier develops (Phelps, 1972), astrocytes and their precursors have been implicated in the induction of the BBB (Goldstein, 1988). The fully mature BBB consists of a complex cellular system of highly specialized endothelial cells, a large number of pericytes embedded in the basal membrane, perivascular macrophages and astrocytic endfeet and until now it is a matter of debate, which 
cell types or components are indeed important for differentiation and maintenance of the BBB (Engelhardt, 2003).

Given the profound astroglial alterations at postnatal stages in the cortical gray matter, we were surprised to observe fully functional BBB characteristics. However, the role of astrocytes in $\mathrm{BBB}$ formation is still controversial, also in light of the early appearance of some $\mathrm{BBB}$ characteristics in brain endothelial cells prior to astrocyte differentiation (Engelhardt, 2003). Based on our analysis we can only conclude that $\beta 1$-integrin on astrocytes (and neurons) is not required for BBB formation and maintenance, at least not after the first postnatal week. However, other integrin isoforms have been implicated in BBB development, such as $\alpha 6 \beta 4$ that is also expressed at the astrocyte endfeet (Wagner et al., 1997; del Zoppo and Milner, 2006) and upregulated in neoplastic and reactive astrocytes (Fasen et al., 2003; Su et al., 2008).

\section{The role of $\beta 1$-integrin in astrocyte and stem cell proliferation}

Notably, $\beta 1$-integrin deficient astrocytes recapitulated many, but not all aspects of reactive gliosis. After a stab wound injury, about half of all astrocytes resume proliferation (Buffo et al., 2008) and around $10 \%$ of these also readopt neural stem cell properties (Buffo et al., 2008). Whereas the proportion of BrdU-incorporating astrocytes varies between different types of trauma and is related to the severity of injury (Buffo et al., 2005; Myer et al., 2006; Buffo et al., 2008) this response is clearly not elicited by conditional $\beta 1$-integrin deletion as even after two weeks of continuous BrdU application only 3\% of the GFAP-positive astrocytes had incorporated BrdU in the $\beta 1-/-$ cortex. Moreover, no cells with neural stem cell properties could be isolated 
from the $\beta 1 /$ - cortex parenchyma comparable to the uninjured WT cortex (data not shown), in pronounced contrast to the reproducible neurosphere formation from cortical cells after stab wound injury (Buffo et al., 2008). These data therefore imply either integrin receptors that are composed of other $\beta$ subunits, such as $\alpha 6 \beta 4$ that is also expressed in astrocytes (del Zoppo and Milner, 2006) and/or one or several of the many growth factors released after injury as potential regulators of this aspect of reactive gliosis. For example, FGF and EGF signaling is pronouncedly increased after brain injury (Clarke et al., 2001; Smith and Strunz, 2005), two signaling pathways well known to affect radial glial cells, the closest relatives of adult astrocytes, during development (Vaccarino et al., 2001; Smith et al., 2006; Sirko et al., 2007). Likewise purinergic signaling via ATP release is one of the first reactions to tissue damage and well known to stimulate astrocyte proliferation .(Neary and Kang, 2005). Interestingly, all of these signaling pathways have also been implicated in the regulation of proliferation in the neural stem cell niches in the forebrain (Kuhn et al., 1997; Doetsch et al., 2002; Braun et al., 2003; Shukla et al., 2005). As the adult neural stem cells in the neurogenic niches have been identified as astrocytelike cells (Doetsch et al., 1997; Alvarez-Buylla et al., 2001), these pathways may well be involved in the regulation of astrocyte/stem cell proliferation as well as in the reinstruction of proliferation and stem cell features in astrocytes after injury. Intriguingly, EGF infusion into the ventricle indeed leads to the up-regulation of Tenascin-C and an apparently hypertrophic reactive phenotype of the astrocyte/stem cells in this region. Thus, these and other growth factors appear to be the key signals to regulate astroglial and stem cell proliferation. From our mutant analysis we can add that $\beta 1$-integrin is apparently not needed to mediate such growth factor 
signaling, as proliferation of reactive astrocytes after stab wound injury was not affected in the hGFAP-Cre- $\beta 1-/-$ (data not shown). Thus, despite the well-known interaction between integrins and growth factor receptors (see e.g. (Colognato et al., 2002), at least $\beta 1$ integrin is dispensible for the signals eliciting proliferation of reactive astrocytes, microglia and NG2 glia after stab wound injury.

\section{Conclusions}

Taken together, our data demonstrate a key role of $\beta 1$-integrin mediated signaling in astrocytes, specifically for maintaining their mature non-hypertrophic resting state. Loss of this signaling causes most of the changes that normally occur in reactive astrocytes, except their proliferation. Thus, our data imply the loss of $\beta 1$-integrinmediated signaling as a key event in the formation of reactive glia and hence also in scar formation. Reactive astrocytes up-regulate and secrete various ECM components such as ChSPGs and Tenascins (McKeon et al., 1991; Steindler et al., 1995; Joester and Faissner, 2001; Grimpe and Silver, 2002; Mizuno et al., 2008), that all contribute to inhibit axonal regeneration. As our data now imply loss of $\beta 1$ integrin-mediated signalling as a core component in this pathway, its activation may provide a novel approach to avoid several negative aspects of reactive gliosis after injury. These considerations highlight the importance of understanding the distinct pathways regulating different aspects of glial reactivity in response to injury.

\section{Figure legends}


Figure 1: $\beta 1$ integrin protein reduction in $\beta 1-/$ mice.

Western Blot analysis $\square$ of $\beta 1$-integrin protein expression levels in cortices at embryonic stage E13 and E17 (A) or at the time of birth (P0) (B) of wildtype (WT) and mutant ( $\beta 1-/-)$ animals. (C) Expression levels of $\beta 1$-integrin protein at P7 in the cortex, basal ganglia, diencephalon, midbrain, hindbrain and spinal cord of WT and $\beta 1-/$ - mice. Anti-tubulin antibody was used as loading control (AC). $\beta 1-$ - conditional knock-out mice; BG basal ganglia; CTX cortex; Dien diencephalon; $H B$ hindbrain; $M B$ midbrain; $S C$ spinal cord; $W T$ control mice.

Figure 2: Partial gliosis in the adult $\beta 1-/$ - mice.

Immunostaining for the astrocytic marker GFAP in WT (A) or $\beta 1$-/- cortices (C). Gray matter (GM) astrocytes were labeled using antibodies against $S 100 \beta$ and glutamine synthase (GS) in WT (B, B') and $\beta 1-/$ - brains (D, D'). A subpopulation of the $\beta 1-/-G M$ astrocytes was immunoreactive for vimentin (F-F"), normally a marker for less mature or reactive astrocytes that is not present in GM astrocytes of WT animals (E-E'). Protein expression of the extracellular matrix molecules Tenascin-C (G-H") and DSD-1, recognized by the 473HD antibody (I-K"), was analyzed by immunohistochemistry. GM gray matter; GS glutamine synthase; $W M$ white matter.

Figure 3: Partial activation of microglia in adult $\beta 1 / /$ - mice.

Immunostaining for microglia using the lba1 antibody (A, B, A', B', C, C') and activated microglia and endothelial cells using an antibody against lectin-GSA (A, A", B, B", C, C") in WT (A-A"), $\beta 1$-/- (B-B") and stab wounded mice (C-C").

Figure 4: The blood brain barrier is still intact in $\beta 1-/-$ mice.

The integrity of the blood brain barrier was tested by injecting Evans blue $(A)$ and dextran-fluorescein (B, C, D) intraperitonealy in $\beta 1-/$ mice and analyzing intact brain hemispheres $(A, B, C)$ in comparison to the stab wounded control site (D). Ctx cortex; sw stab wound

Figure 5: Basement membrane disruption occurred only in older $\beta 1-/-$ animals. Immunostainings for the basement membrane components laminin ( $\left.A, A^{\prime}\right)$, perlecan (B), collagenIV (C, $\left.C^{\prime}\right)$ and fibronectin (D) in cortices of two month old animals (A-D) and for collagenIV (E, E') in brains of six month old mice. 
Figure 6: Ultrastructural analysis of the basement membrane in six month old animals.

Electronmicrocopical study of the leptomenigeal basement membrane (black arrows) of WT (A) and $\beta 1-/$ - (B) cortices (defects of the zipper-like structure were seen as bright spots separating the two BM sheaths, red arrows) and the perivascular basement membrane of WT (A', A') and $\beta 1-/-\left(B^{\prime}, B^{\prime \prime}\right)$ cortices around brain capillaries. $A E$ astrocyte endfeet; $B M$ basement membrane; $C$ capillary wall; $L$ capillary lumen

Figure 7: The polarity of gray matter astrocytes was impaired.

Immunostainings for the astrocyte endfeet proteins aquaporin-4 (A-B'), $\alpha-$ dystrobrevin (C-D') and dystrophin (E-F') in WT and $\beta 1 /-$ mice. Aqp4 aquaporin4

Figure 8: Impaired polarized secretion of astrocytic laminin isoforms.

Astrocyte-derived laminins were labeled using specific antibodies against the $\alpha 1$ $(A, B)$ and $\alpha 2(C, D)$ chains in WT and $\beta 1-/$ cortices. Likewise the endothelial cell-derived laminin chains $\alpha 4(E, F)$ and $\alpha 5(G, H)$ were labeled in both, WT and $\beta 1-/$ - cortices. $L N$ laminin

Figure 9: Neuron specific deletion of $\beta 1$-integrin gene did not lead to gliosis. Immunostaining against GFAP in the cortical gray matter and white matter (insert in $\mathrm{B}$ ) of $\mathrm{WT}(\mathrm{A})$ and Nex::Cre,f $\mathrm{f} / \mathrm{f} \beta 1$ (B) mice. GM gray matter; $W M$ white matter

Suppl. Figure 1: Brain morphology, axons and myelin.

Brains of WT (A) and $\beta 1-/$ - animals (B). Immunostaining for the dendrite marker microtubule-associated protein 2 in WT (C) and mutant cortices (D). Stainings against antigens of the myelin proteins proteolipid protein (E, F) and myelinassociated glycoprotein $(\mathrm{G}, \mathrm{H})$ in WT $(\mathrm{E}, \mathrm{G})$ and $\beta 1-/$ - brains $(F, H)$. MAG myelin-associated glycoprotein; MAP2 microtubule-associated protein 2; PLP proteolipid protein

Suppl. Figure 2: GFAP up-regulation all over the brain.

GFAP protein expression was analyzed by immunostaining in the cortex $(A, B)$, basal ganglia $(A, B)$, corpus callosum $(A, B)$, diencepalon $(C, D)$, midbrain $(E, F)$, 
cerebellum $(\mathrm{G}, \mathrm{H})$ and hindbrain $(\mathrm{I}, \mathrm{K})$ of $\beta 1-/$ - and WT brains of two month old animals. $B G$ basal ganglia; $C B$ cerebellum; $C C$ corpus callosum; $C T X$ cortex; dien diencephalon; $H B$ hindbrain; $M B$ midbrain

Suppl. Figure 3: GFAP upregulation in the spinal cord gray matter of $\beta 1-/-$ animals. Immunostaining for the intermediate filament GFAP in the spinal cord gray matter of WT (A, $\left.A^{\prime}\right)$ and $\beta 1 /-\left(B, B^{\prime}\right)$ animals. GFAP immunostaining in the spinal cord white matter of WT (C) and $\beta 1 / /$ (D) animals.

Suppl. Figure 4: No cell death after deletion of $\beta 1$-integrin.

Cell death was investigated either by Cresyl violet (Nissl) staining in WT (A, A') and $\beta 1 /$ - cortices (B, B') or by staining against activated caspase 3 (C-D').

Suppl. Figure 5: Development of the partial gliosis phenotype.

The development of the GFAP upregulation was examined at the time of birth $(A, B)$, at postnatal day $4(G, H)$, two $(N, O)$ and three $(P, Q)$ weeks after the birth of WT and $\beta 1-/$ - animals. The astrocytic laminin $\alpha 1$ (C, D and I, K) and $\alpha 2$ $(E, F$ and $L, M)$ chains were analyzed in comparison for the first two timepoints.

Suppl. figure 6: GFAP upregulation during development in other brain regions. GFAP expression levels were investigated in 26 days old WT and $\beta 1-/$ - mice in the striatum $(A, B)$, diencephalon $(C, D)$ and hindbrain $(E, F) . C C$ corpus callosum; dien diencephalon; fim hippocampal fimbria; $L V$ lateral ventricle; stri striatum

\section{References}

Alvarez-Buylla A, Garcia-Verdugo JM, Tramontin AD (2001) A unified hypothesis on the lineage of neural stem cells. Nat Rev Neurosci 2:287-293.

Araque A (2006) Astrocyte-neuron signaling in the brain--implications for disease. Curr Opin Investig Drugs 7:619-624.

Barry D, McDermott K (2005) Differentiation of radial glia from radial precursor cells and transformation into astrocytes in the developing rat spinal cord. Glia 50:187-197. 
Beggs HE, Schahin-Reed D, Zang K, Goebbels S, Nave KA, Gorski J, Jones KR, Sretavan D, Reichardt LF (2003) FAK deficiency in cells contributing to the basal lamina results in cortical abnormalities resembling congenital muscular dystrophies. Neuron 40:501-514.

Belvindrah R, Graus-Porta D, Goebbels S, Nave KA, Muller U (2007a) Beta1 integrins in radial glia but not in migrating neurons are essential for the formation of cell layers in the cerebral cortex. J Neurosci 27:13854-13865.

Belvindrah R, Hankel S, Walker J, Patton BL, Muller U (2007b) Beta1 integrins control the formation of cell chains in the adult rostral migratory stream. J Neurosci 27:2704-2717.

Belvindrah R, Nalbant P, Ding S, Wu C, Bokoch GM, Muller U (2006) Integrin-linked kinase regulates Bergmann glial differentiation during cerebellar development. Mol Cell Neurosci 33:109-125.

Benninger $\mathrm{Y}$, Colognato $\mathrm{H}$, Thurnherr T, Franklin RJ, Leone DP, Atanasoski S, Nave KA, Ffrench-Constant C, Suter U, Relvas JB (2006) Beta1-integrin signaling mediates premyelinating oligodendrocyte survival but is not required for CNS myelination and remyelination. J Neurosci 26:7665-7673.

Blaess S, Graus-Porta D, Belvindrah R, Radakovits R, Pons S, Littlewood-Evans A, Senften M, Guo H, Li Y, Miner JH, Reichardt LF, Muller U (2004) Beta1-integrins are critical for cerebellar granule cell precursor proliferation. J Neurosci 24:3402-3412.

Bragg AD, Amiry-Moghaddam M, Ottersen OP, Adams ME, Froehner SC (2006) Assembly of a perivascular astrocyte protein scaffold at the mammalian blood-brain barrier is dependent on alpha-syntrophin. Glia 53:879-890.

Brakebusch C, Fassler R (2005) beta 1 integrin function in vivo: adhesion, migration and more. Cancer Metastasis Rev 24:403-411.

Brakebusch C, Grose R, Quondamatteo F, Ramirez A, Jorcano JL, Pirro A, Svensson M, Herken R, Sasaki T, Timpl R, Werner S, Fassler R (2000) Skin and hair follicle integrity is crucially dependent on beta 1 integrin expression on keratinocytes. Embo J 19:39904003.

Braun N, Sevigny J, Mishra SK, Robson SC, Barth SW, Gerstberger R, Hammer K, Zimmermann $H$ (2003) Expression of the ecto-ATPase NTPDase2 in the germinal zones of the developing and adult rat brain. Eur J Neurosci 17:1355-1364.

Brightman MW (1968) The intracerebral movement of proteins injected into blood and cerebrospinal fluid of mice. Prog Brain Res 29:19-40.

Brightman MW, Kaya M (2000) Permeable endothelium and the interstitial space of brain. Cell Mol Neurobiol 20:111-130. 
Buffo A, Vosko MR, Erturk D, Hamann GF, Jucker M, Rowitch D, Gotz M (2005) Expression pattern of the transcription factor Olig2 in response to brain injuries: implications for neuronal repair. Proc Natl Acad Sci U S A 102:18183-18188.

Buffo A, Rite I, Tripathi P, Lepier A, Colak D, Horn AP, Mori T, Gotz M (2008) Origin and progeny of reactive gliosis: A source of multipotent cells in the injured brain. Proc Natl Acad Sci U S A 105:3581-3586.

Busch SA, Silver J (2007) The role of extracellular matrix in CNS regeneration. Curr Opin Neurobiol 17:120-127.

Bush TG, Puvanachandra N, Horner CH, Polito A, Ostenfeld T, Svendsen CN, Mucke L, Johnson MH, Sofroniew MV (1999) Leukocyte infiltration, neuronal degeneration, and neurite outgrowth after ablation of scar-forming, reactive astrocytes in adult transgenic mice. Neuron 23:297-308.

Cappello S, Attardo A, Wu X, Iwasato T, Itohara S, Wilsch-Brauninger M, Eilken HM, Rieger MA, Schroeder TT, Huttner WB, Brakebusch C, Gotz M (2006) The Rho-GTPase cdc42 regulates neural progenitor fate at the apical surface. Nat Neurosci 9:1099-1107.

Chang CY, Chien HF, Jiangshieh YF, Wu CH (2003) Microglia in the olfactory bulb of rats during postnatal development and olfactory nerve injury with zinc sulfate: a lectin labeling and ultrastrucutural study. Neurosci Res 45:325-333.

Clarke WE, Berry M, Smith C, Kent A, Logan A (2001) Coordination of fibroblast growth factor receptor 1 (FGFR1) and fibroblast growth factor-2 (FGF-2) trafficking to nuclei of reactive astrocytes around cerebral lesions in adult rats. Mol Cell Neurosci 17:17-30.

Colognato H, Baron W, Avellana-Adalid V, Relvas JB, Baron-Van Evercooren A, GeorgesLabouesse $E$, ffrench-Constant $C$ (2002) CNS integrins switch growth factor signalling to promote target-dependent survival. Nat Cell Biol 4:833-841.

del Zoppo GJ, Milner R (2006) Integrin-matrix interactions in the cerebral microvasculature. Arterioscler Thromb Vasc Biol 26:1966-1975.

Dimou L, Simon C, Kirchhoff F, Takebayashi H, Gotz M (2008) Progeny of Olig2-expressing progenitors in the gray and white matter of the adult mouse cerebral cortex. J Neurosci 28:10434-10442.

Doetsch F, Garcia-Verdugo JM, Alvarez-Buylla A (1997) Cellular composition and threedimensional organization of the subventricular germinal zone in the adult mammalian brain. J Neurosci 17:5046-5061.

Doetsch F, Petreanu L, Caille I, Garcia-Verdugo JM, Alvarez-Buylla A (2002) EGF converts transit-amplifying neurogenic precursors in the adult brain into multipotent stem cells. Neuron 36:1021-1034.

Engelhardt B (2003) Development of the blood-brain barrier. Cell Tissue Res 314:119-129. 
Fasen K, Elger CE, Lie AA (2003) Distribution of alpha and beta integrin subunits in the adult rat hippocampus after pilocarpine-induced neuronal cell loss, axonal reorganization and reactive astrogliosis. Acta Neuropathol (Berl) 106:319-322.

Gadea A, Schinelli S, Gallo V (2008) Endothelin-1 regulates astrocyte proliferation and reactive gliosis via a JNK/C-Jun signaling pathway. J Neurosci 28:2394-2408.

Garwood J, Rigato F, Heck N, Faissner A (2001) Tenascin glycoproteins and the complementary ligand DSD-1-PG/ phosphacan--structuring the neural extracellular matrix during development and repair. Restor Neurol Neurosci 19:51-64.

Georges-Labouesse E, Mark M, Messaddeq N, Gansmuller A (1998) Essential role of alpha 6 integrins in cortical and retinal lamination. Curr Biol 8:983-986.

Goebbels S, Bormuth I, Bode U, Hermanson O, Schwab MH, Nave KA (2006) Genetic targeting of principal neurons in neocortex and hippocampus of NEX-Cre mice. Genesis 44:611621.

Goldstein GW (1988) Endothelial cell-astrocyte interactions. A cellular model of the blood-brain barrier. Ann N Y Acad Sci 529:31-39.

Graus-Porta D, Blaess S, Senften M, Littlewood-Evans A, Damsky C, Huang Z, Orban P, Klein R, Schittny JC, Muller U (2001) Beta1-class integrins regulate the development of laminae and folia in the cerebral and cerebellar cortex. Neuron 31:367-379.

Grimpe B, Silver J (2002) The extracellular matrix in axon regeneration. Prog Brain Res 137:333-349.

Hanisch UK, Kettenmann H (2007) Microglia: active sensor and versatile effector cells in the normal and pathologic brain. Nat Neurosci 10:1387-1394.

Hartfuss E, Galli R, Heins N, Gotz M (2001) Characterization of CNS precursor subtypes and radial glia. Dev Biol 229:15-30.

Haubst N, Georges-Labouesse E, De Arcangelis A, Mayer U, Gotz M (2006) Basement membrane attachment is dispensable for radial glial cell fate and for proliferation, but affects positioning of neuronal subtypes. Development 133:3245-3254.

Herms J, Anliker B, Heber S, Ring S, Fuhrmann M, Kretzschmar H, Sisodia S, Muller U (2004) Cortical dysplasia resembling human type 2 lissencephaly in mice lacking all three APP family members. EMBO J 23:4106-4115.

Herrmann JE, Imura T, Song B, Qi J, Ao Y, Nguyen TK, Korsak RA, Takeda K, Akira S, Sofroniew MV (2008) STAT3 is a critical regulator of astrogliosis and scar formation after spinal cord injury. J Neurosci 28:7231-7243.

Huang Z, Shimazu K, Woo NH, Zang K, Muller U, Lu B, Reichardt LF (2006) Distinct roles of the beta 1-class integrins at the developing and the mature hippocampal excitatory synapse. J Neurosci 26:11208-11219. 
landiev I, Pannicke T, Biedermann B, Wiedemann P, Reichenbach A, Bringmann A (2006) Ischemia-reperfusion alters the immunolocalization of glial aquaporins in rat retina. Neurosci Lett 408:108-112.

Joester A, Faissner A (2001) The structure and function of tenascins in the nervous system. Matrix Biol 20:13-22.

Kagami S, Kondo S (2004) Beta1-integrins and glomerular injury. J Med Invest 51:1-13.

Kawaguchi A, Miyata T, Sawamoto K, Takashita N, Murayama A, Akamatsu W, Ogawa M, Okabe M, Tano Y, Goldman SA, Okano H (2001) Nestin-EGFP transgenic mice: visualization of the self-renewal and multipotency of CNS stem cells. Mol Cell Neurosci 17:259-273.

Kettenmann H, Ransom BR (2005) Neuroglia, 2nd Edition. Oxford: Oxford University Press.

Kozler P, Pokorny J (2003) Altered blood-brain barrier permeability and its effect on the distribution of Evans blue and sodium fluorescein in the rat brain applied by intracarotid injection. Physiol Res 52:607-614.

Kuhn HG, Winkler J, Kempermann G, Thal LJ, Gage FH (1997) Epidermal growth factor and fibroblast growth factor-2 have different effects on neural progenitors in the adult rat brain. J Neurosci 17:5820-5829.

Malatesta P, Hack MA, Hartfuss E, Kettenmann H, Klinkert W, Kirchhoff F, Gotz M (2003) Neuronal or glial progeny: regional differences in radial glia fate. Neuron 37:751-764.

Mathewson AJ, Berry M (1985) Observations on the astrocyte response to a cerebral stab wound in adult rats. Brain Res 327:61-69.

McKeon RJ, Schreiber RC, Rudge JS, Silver J (1991) Reduction of neurite outgrowth in a model of glial scarring following CNS injury is correlated with the expression of inhibitory molecules on reactive astrocytes. J Neurosci 11:3398-3411.

McMahon SS, McDermott KW (2007) Developmental potential of radial glia investigated by transplantation into the developing rat ventricular system in utero. Exp Neurol 203:128136.

Milner R, Hung S, Wang X, Spatz M, del Zoppo GJ (2008) The rapid decrease in astrocyteassociated dystroglycan expression by focal cerebral ischemia is protease-dependent. $\mathrm{J}$ Cereb Blood Flow Metab 28:812-823.

Mizuno H, Warita H, Aoki M, Itoyama $\mathrm{Y}$ (2008) Accumulation of chondroitin sulfate proteoglycans in the microenvironment of spinal motor neurons in amyotrophic lateral sclerosis transgenic rats. J Neurosci Res 86:2512-2523.

Moore SA, Saito F, Chen J, Michele DE, Henry MD, Messing A, Cohn RD, Ross-Barta SE, Westra S, Williamson RA, Hoshi T, Campbell KP (2002) Deletion of brain dystroglycan recapitulates aspects of congenital muscular dystrophy. Nature 418:422-425. 
Morgenstern DA, Asher RA, Fawcett JW (2002) Chondroitin sulphate proteoglycans in the CNS injury response. Prog Brain Res 137:313-332.

Mori T, Buffo A, Gotz M (2005) The novel roles of glial cells revisited: the contribution of radial glia and astrocytes to neurogenesis. Curr Top Dev Biol 69:67-99.

Myer DJ, Gurkoff GG, Lee SM, Hovda DA, Sofroniew MV (2006) Essential protective roles of reactive astrocytes in traumatic brain injury. Brain 129:2761-2772.

Neary JT, Kang Y (2005) Signaling from P2 nucleotide receptors to protein kinase cascades induced by CNS injury: implications for reactive gliosis and neurodegeneration. Mol Neurobiol 31:95-103.

Nesic O, Lee J, Ye Z, Unabia GC, Rafati D, Hulsebosch CE, Perez-Polo JR (2006) Acute and chronic changes in aquaporin 4 expression after spinal cord injury. Neuroscience 143:779-792.

Novak A, Guo C, Yang W, Nagy A, Lobe CG (2000) Z/EG, a double reporter mouse line that expresses enhanced green fluorescent protein upon Cre-mediated excision. Genesis 28:147-155.

Okada S, Nakamura M, Katoh H, Miyao T, Shimazaki T, Ishii K, Yamane J, Yoshimura A, Iwamoto Y, Toyama Y, Okano H (2006) Conditional ablation of Stat3 or Socs3 discloses a dual role for reactive astrocytes after spinal cord injury. Nat Med 12:829-834.

Pekny M, Nilsson M (2005) Astrocyte activation and reactive gliosis. Glia 50:427-434.

Pekny M, Wilhelmsson U, Bogestal YR, Pekna M (2007) The role of astrocytes and complement system in neural plasticity. Int Rev Neurobiol 82:95-111.

Phelps CH (1972) The development of glio-vascular relationships in the rat spinal cord. An electron microscopic study. Z Zellforsch Mikrosk Anat 128:555-563.

Pinto L, Mader MT, Irmler M, Gentilini M, Santoni F, Drechsel D, Blum R, Stahl R, Bulfone A, Malatesta P, Beckers J, Gotz M (2008) Prospective isolation of functionally distinct radial glial subtypes--lineage and transcriptome analysis. Mol Cell Neurosci 38:15-42.

Potocnik AJ, Brakebusch C, Fassler R (2000) Fetal and adult hematopoietic stem cells require beta1 integrin function for colonizing fetal liver, spleen, and bone marrow. Immunity 12:653-663.

Reichardt LF, Tomaselli KJ (1991) Extracellular matrix molecules and their receptors: functions in neural development. Annu Rev Neurosci 14:531-570.

Reier PJ, Houle JD (1988) The glial scar: its bearing on axonal elongation and transplantation approaches to CNS repair. Adv Neurol 47:87-138.

Ridet JL, Malhotra SK, Privat A, Gage FH (1997) Reactive astrocytes: cellular and molecular cues to biological function. Trends Neurosci 20:570-577. 
Saadoun S, Bell BA, Verkman AS, Papadopoulos MC (2008) Greatly improved neurological outcome after spinal cord compression injury in AQP4-deficient mice. Brain 131:10871098.

Sandvig A, Berry M, Barrett LB, Butt A, Logan A (2004) Myelin-, reactive glia-, and scar-derived CNS axon growth inhibitors: expression, receptor signaling, and correlation with axon regeneration. Glia 46:225-251.

Schroder JE, Tegeler MR, Grosshans U, Porten E, Blank M, Lee J, Esapa C, Blake DJ, Kroger $S$ (2007) Dystroglycan regulates structure, proliferation and differentiation of neuroepithelial cells in the developing vertebrate CNS. Dev Biol 307:62-78.

Schwab MH, Druffel-Augustin S, Gass P, Jung M, Klugmann M, Bartholomae A, Rossner MJ, Nave KA (1998) Neuronal basic helix-loop-helix proteins (NEX, neuroD, NDRF): spatiotemporal expression and targeted disruption of the NEX gene in transgenic mice. J Neurosci 18:1408-1418.

Shukla V, Zimmermann H, Wang L, Kettenmann H, Raab S, Hammer K, Sevigny J, Robson SC, Braun N (2005) Functional expression of the ecto-ATPase NTPDase2 and of nucleotide receptors by neuronal progenitor cells in the adult murine hippocampus. J Neurosci Res 80:600-610.

Sievers J, Pehlemann FW, Gude S, Berry M (1994a) Meningeal cells organize the superficial glia limitans of the cerebellum and produce components of both the interstitial matrix and the basement membrane. J Neurocytol 23:135-149.

Sievers J, Pehlemann FW, Gude S, Berry M (1994b) A time course study of the alterations in the development of the hamster cerebellar cortex after destruction of the overlying meningeal cells with 6-hydroxydopamine on the day of birth. J Neurocytol 23:117-134.

Silver J, Miller JH (2004) Regeneration beyond the glial scar. Nat Rev Neurosci 5:146-156.

Sirko S, von Holst A, Wizenmann A, Gotz M, Faissner A (2007) Chondroitin sulfate glycosaminoglycans control proliferation, radial glia cell differentiation and neurogenesis in neural stem/progenitor cells. Development 134:2727-2738.

Sixt M, Engelhardt B, Pausch F, Hallmann R, Wendler O, Sorokin LM (2001) Endothelial cell laminin isoforms, laminins 8 and 10, play decisive roles in T cell recruitment across the blood-brain barrier in experimental autoimmune encephalomyelitis. J Cell Biol 153:933946.

Smith GM, Strunz C (2005) Growth factor and cytokine regulation of chondroitin sulfate proteoglycans by astrocytes. Glia 52:209-218.

Smith KM, Ohkubo Y, Maragnoli ME, Rasin MR, Schwartz ML, Sestan N, Vaccarino FM (2006) Midline radial glia translocation and corpus callosum formation require FGF signaling. Nat Neurosci 9:787-797. 
Steindler DA, Settles D, Erickson HP, Laywell ED, Yoshiki A, Faissner A, Kusakabe M (1995) Tenascin knockout mice: barrels, boundary molecules, and glial scars. J Neurosci 15:1971-1983.

Stupack DG (2005) Integrins as a distinct subtype of dependence receptors. Cell Death Differ 12:1021-1030.

Su L, Lv X, Miao J (2008) Integrin beta4 in Neural Cells. Neuromolecular Med.

Takada Y, Ye X, Simon S (2007) The integrins. Genome Biol 8:215.

Tran KT, Griffith L, Wells A (2004) Extracellular matrix signaling through growth factor receptors during wound healing. Wound Repair Regen 12:262-268.

Tuori A, Virtanen I, Uusitalo H (1994) Lectin binding in the anterior segment of the bovine eye. Histochem J 26:787-798.

Ulbricht E, Pannicke T, Hollborn M, Raap M, Goczalik I, landiev I, Hartig W, Uhlmann S, Wiedemann P, Reichenbach A, Bringmann A, Francke M (2008) Proliferative gliosis causes mislocation and inactivation of inwardly rectifying $\mathrm{K}(+)$ (Kir) channels in rabbit retinal glial cells. Exp Eye Res 86:305-313.

Vaccarino FM, Ganat Y, Zhang Y, Zheng W (2001) Stem cells in neurodevelopment and plasticity. Neuropsychopharmacology 25:805-815.

Verkman AS, Binder DK, Bloch O, Auguste K, Papadopoulos MC (2006) Three distinct roles of aquaporin-4 in brain function revealed by knockout mice. Biochim Biophys Acta 1758:1085-1093.

Wagner S, Tagaya M, Koziol JA, Quaranta V, del Zoppo GJ (1997) Rapid disruption of an astrocyte interaction with the extracellular matrix mediated by integrin alpha 6 beta 4 during focal cerebral ischemia/reperfusion. Stroke 28:858-865.

Wanner IB, Deik A, Torres M, Rosendahl A, Neary JT, Lemmon VP, Bixby JL (2008) A new in vitro model of the glial scar inhibits axon growth. Glia 56:1691-1709.

Wennerberg K, Armulik A, Sakai T, Karlsson M, Fassler R, Schaefer EM, Mosher DF, Johansson $S$ (2000) The cytoplasmic tyrosines of integrin subunit beta1 are involved in focal adhesion kinase activation. Mol Cell Biol 20:5758-5765.

Wu SX, Goebbels S, Nakamura K, Nakamura K, Kometani K, Minato N, Kaneko T, Nave KA, Tamamaki N (2005) Pyramidal neurons of upper cortical layers generated by NEXpositive progenitor cells in the subventricular zone. Proc Natl Acad Sci U S A 102:17172-17177.

Zhuo L, Theis M, Alvarez-Maya I, Brenner M, Willecke K, Messing A (2001) hGFAP-cre transgenic mice for manipulation of glial and neuronal function in vivo. Genesis 31:8594. 


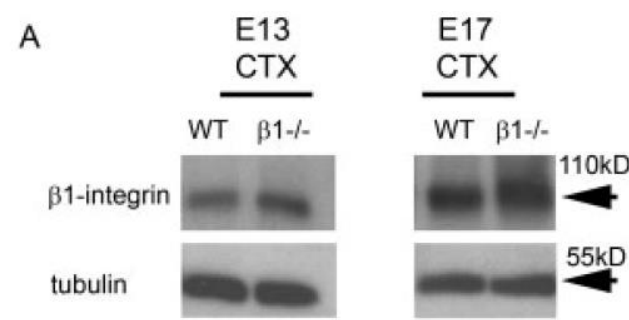

B

PO CTX

$$
\text { WT }
$$

$\beta 1$-integrin

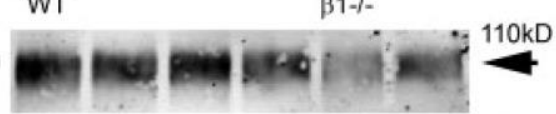
C

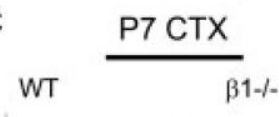

GAP-DH
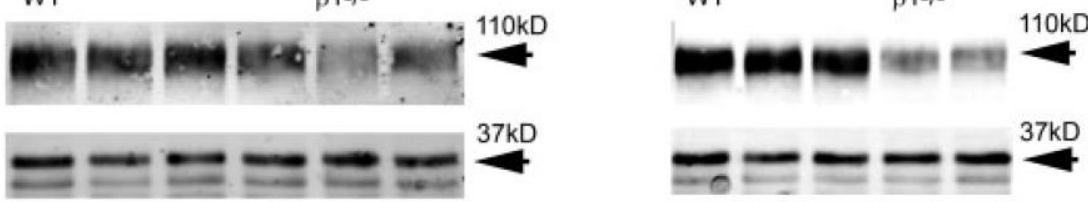

D

E

adult brain regions

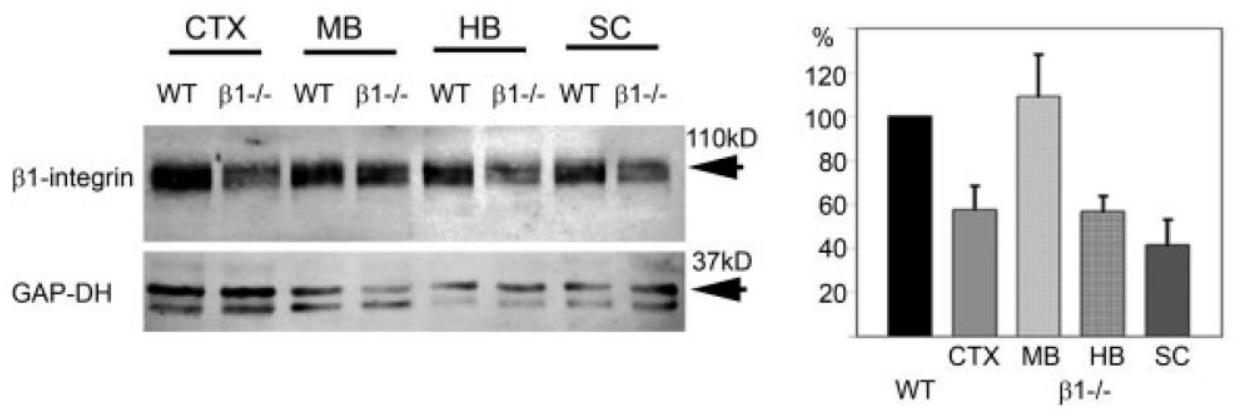

Figure 1 
WT
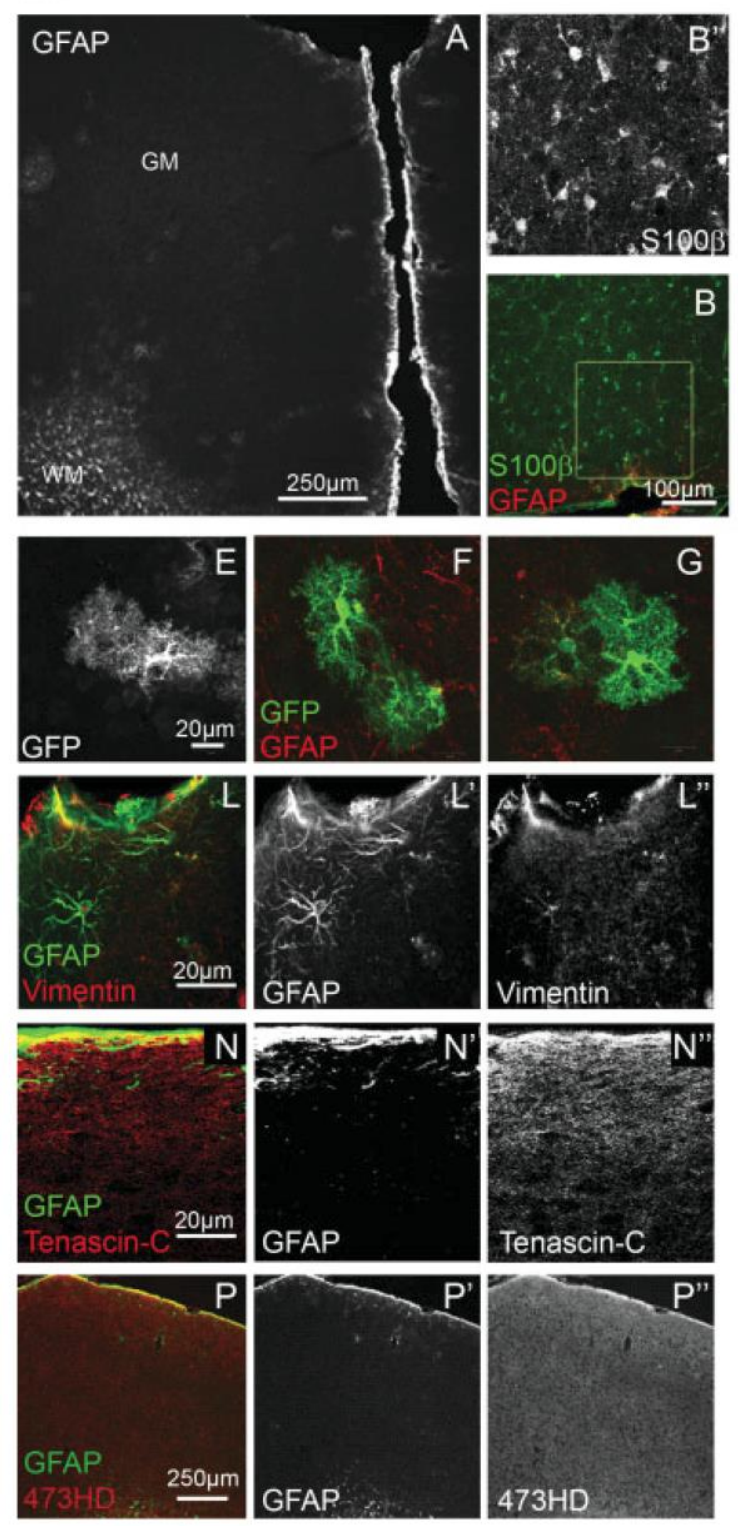

$\beta 1$-integrin -/-
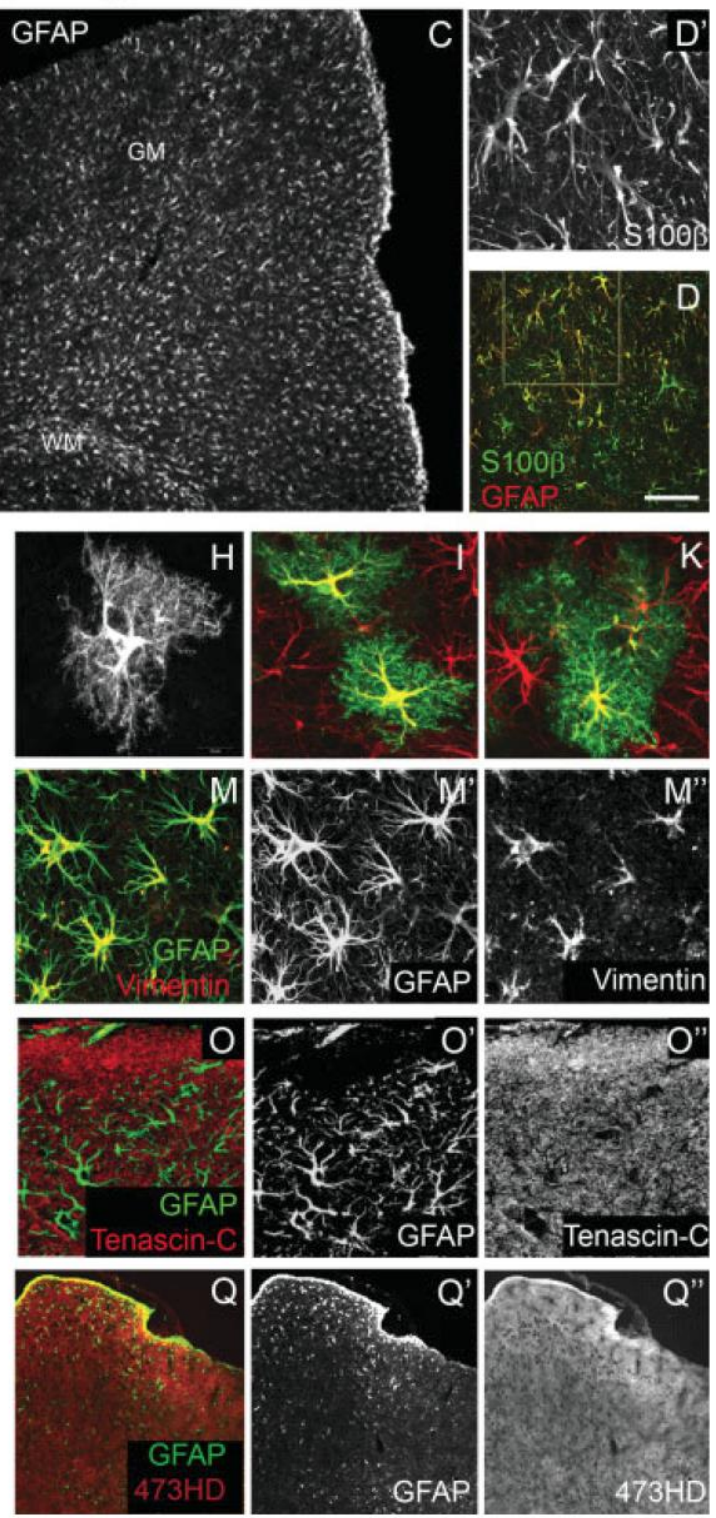

Figure 2 

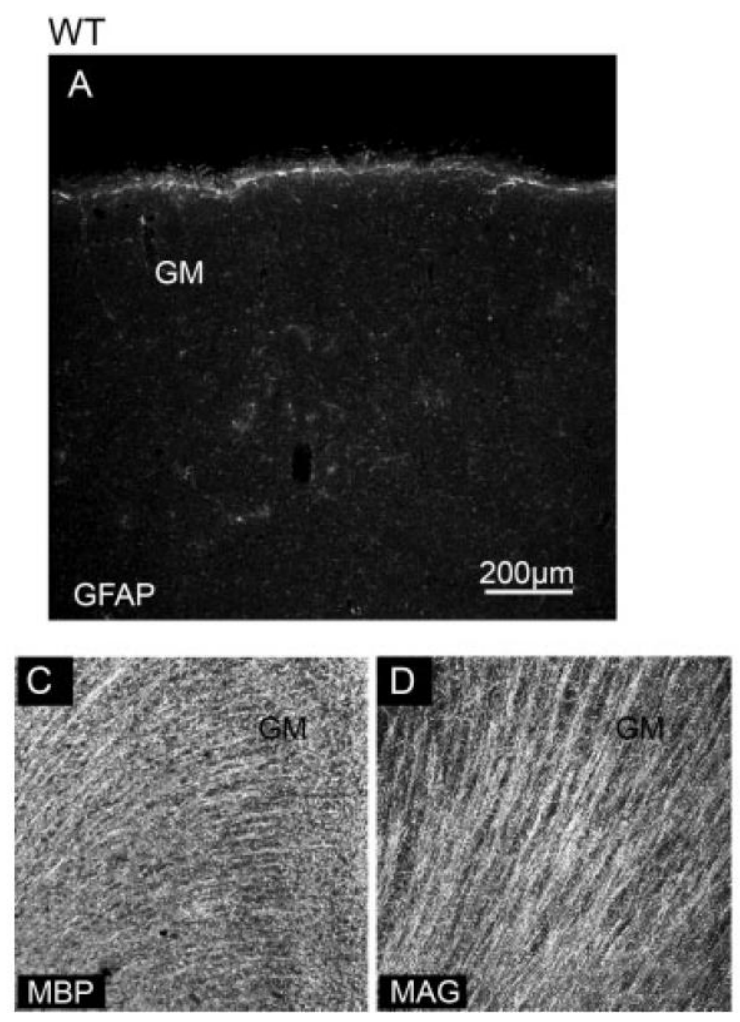
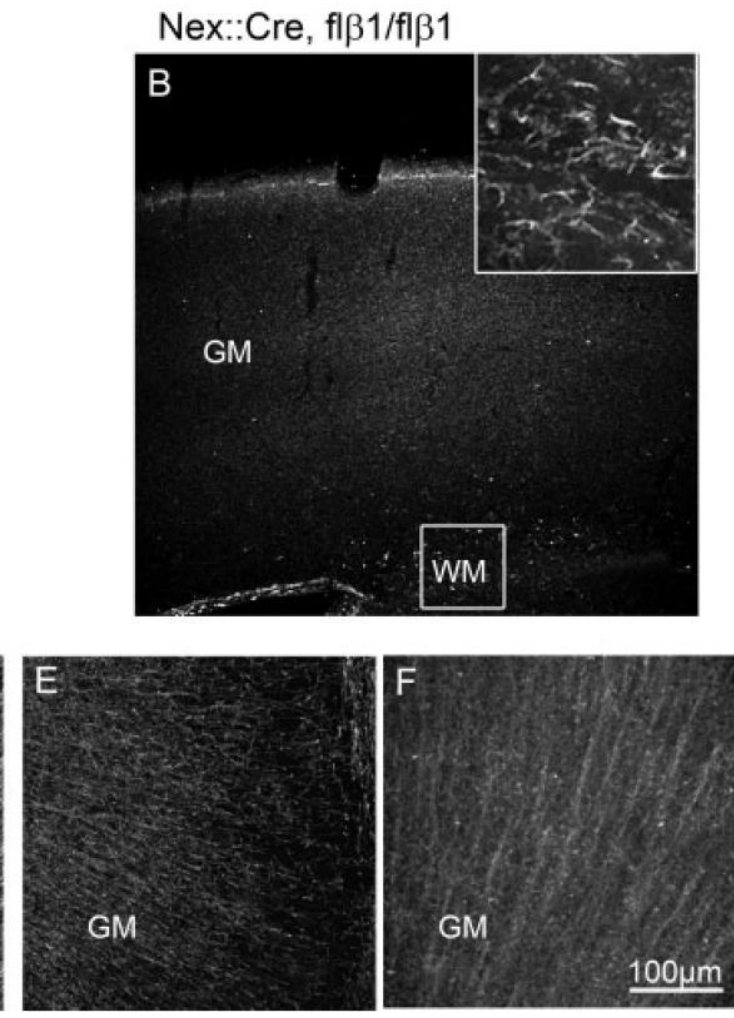

Figure 3 

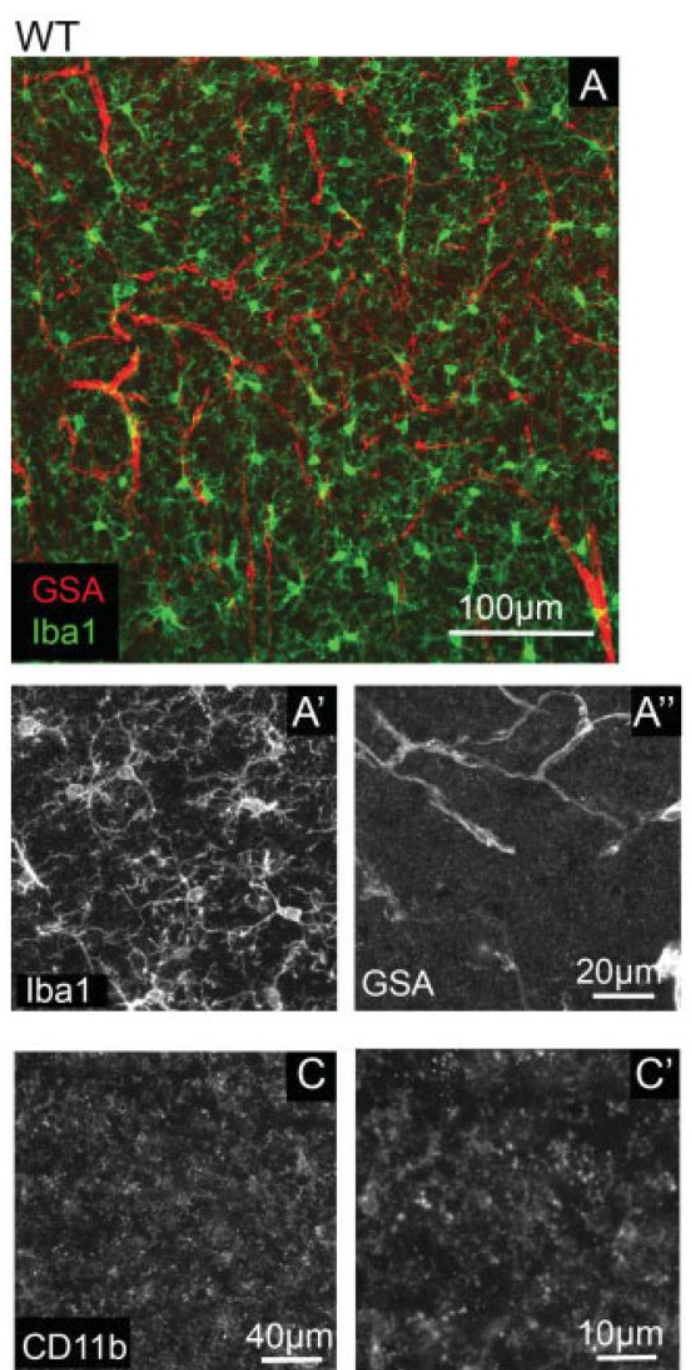

WT stab wound
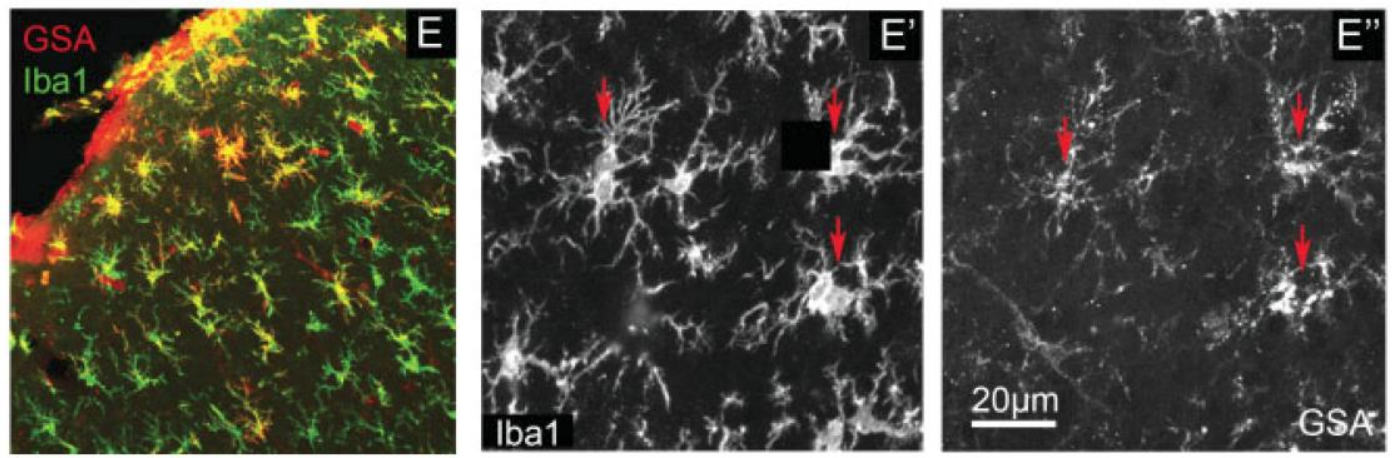

$\beta 1$-integrin -/-
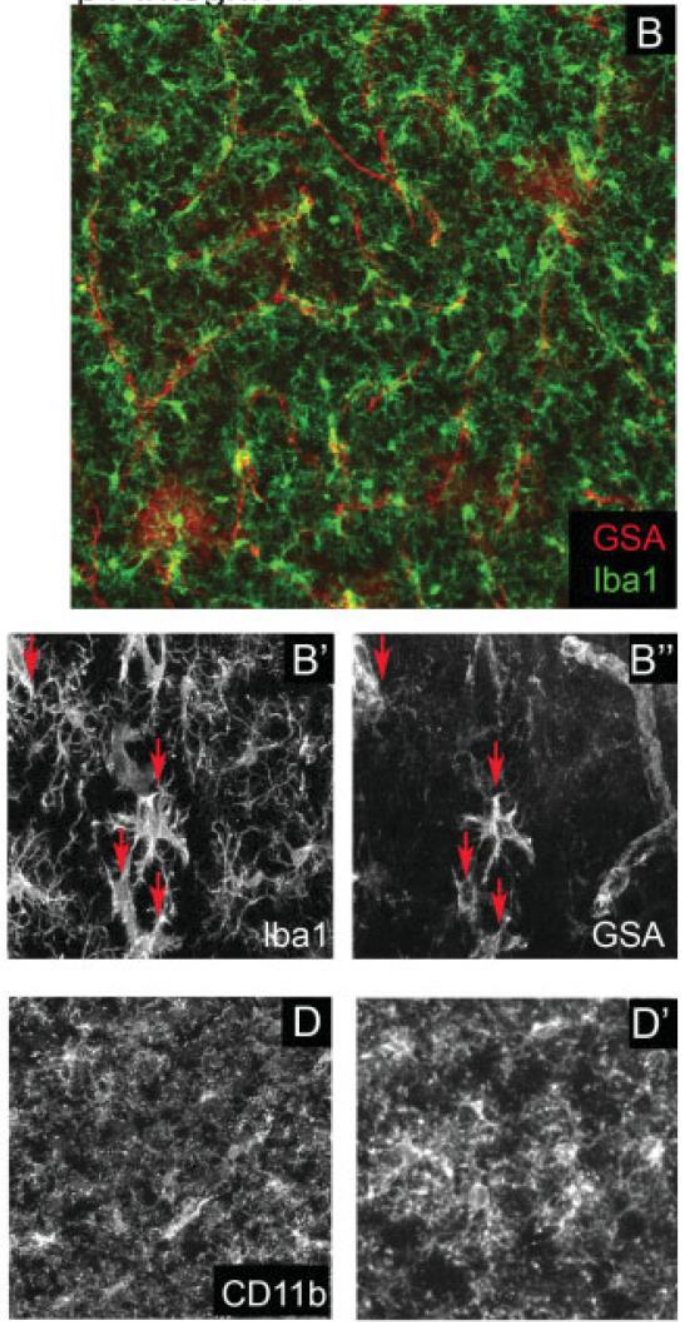

Figure 4

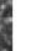


$\beta 1$-integrin -/-

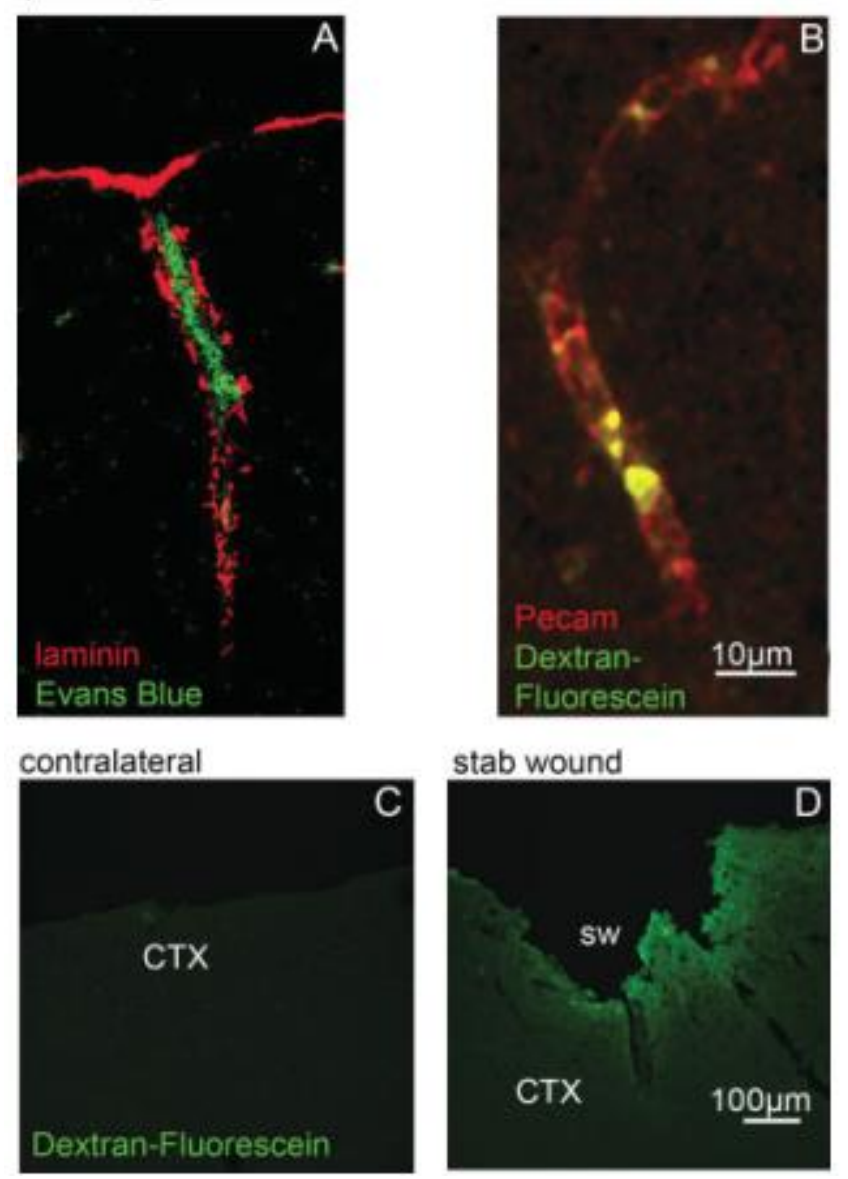

Figure 5 


\section{2 month of age}
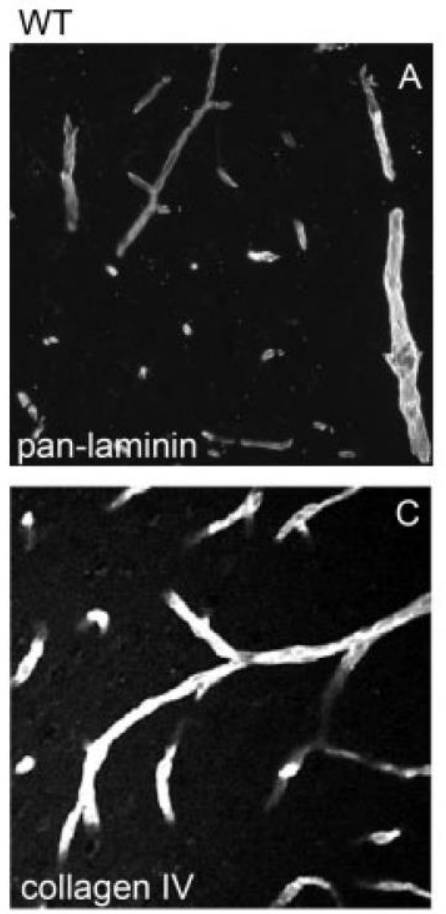

6 month of age

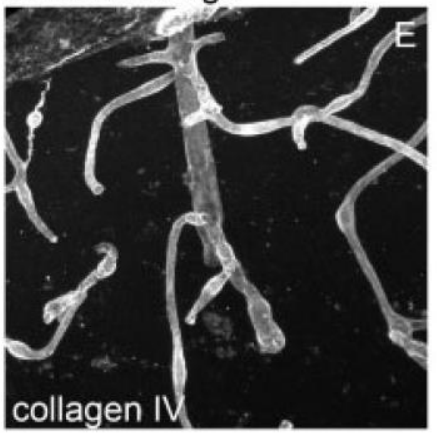

$\beta 1$-integrin -/-
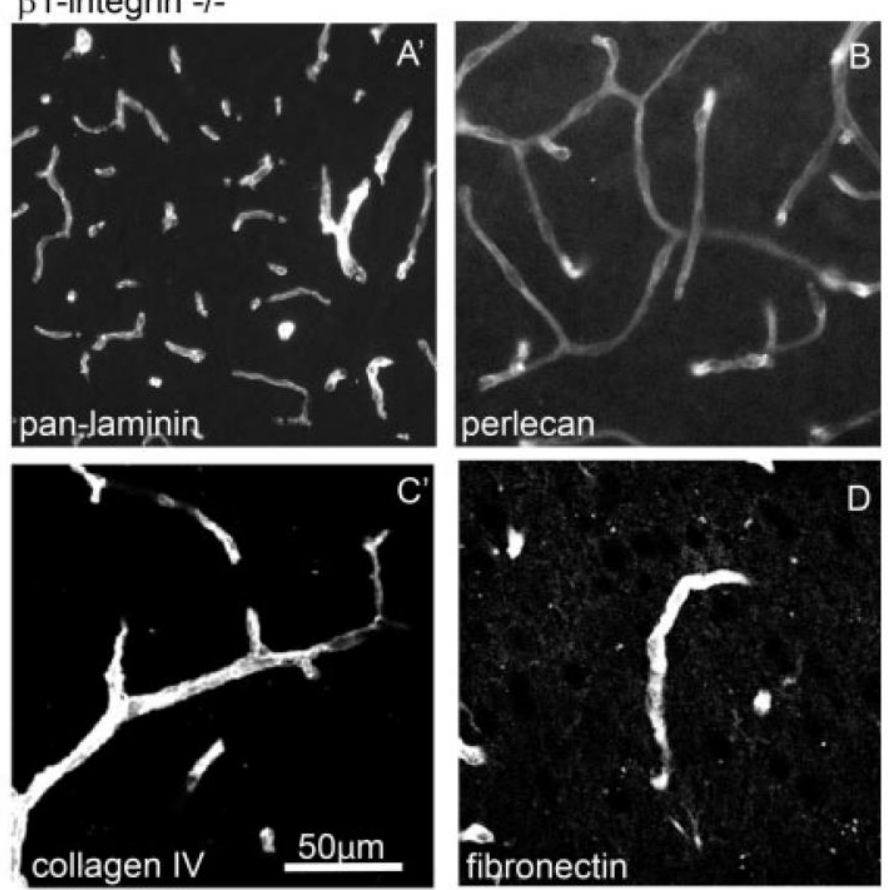

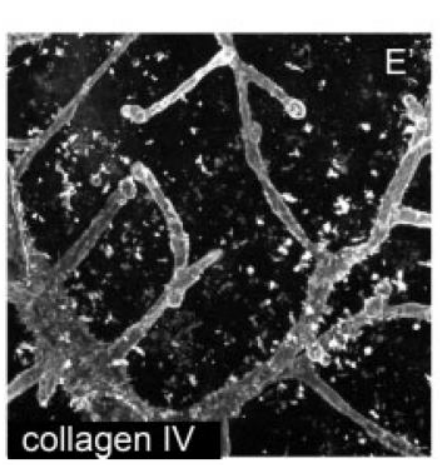

Figure 6 


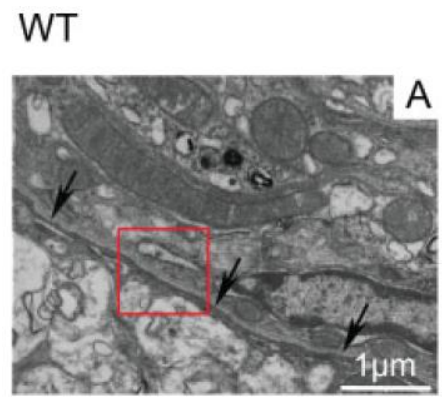

$\beta 1$-integrin -/-
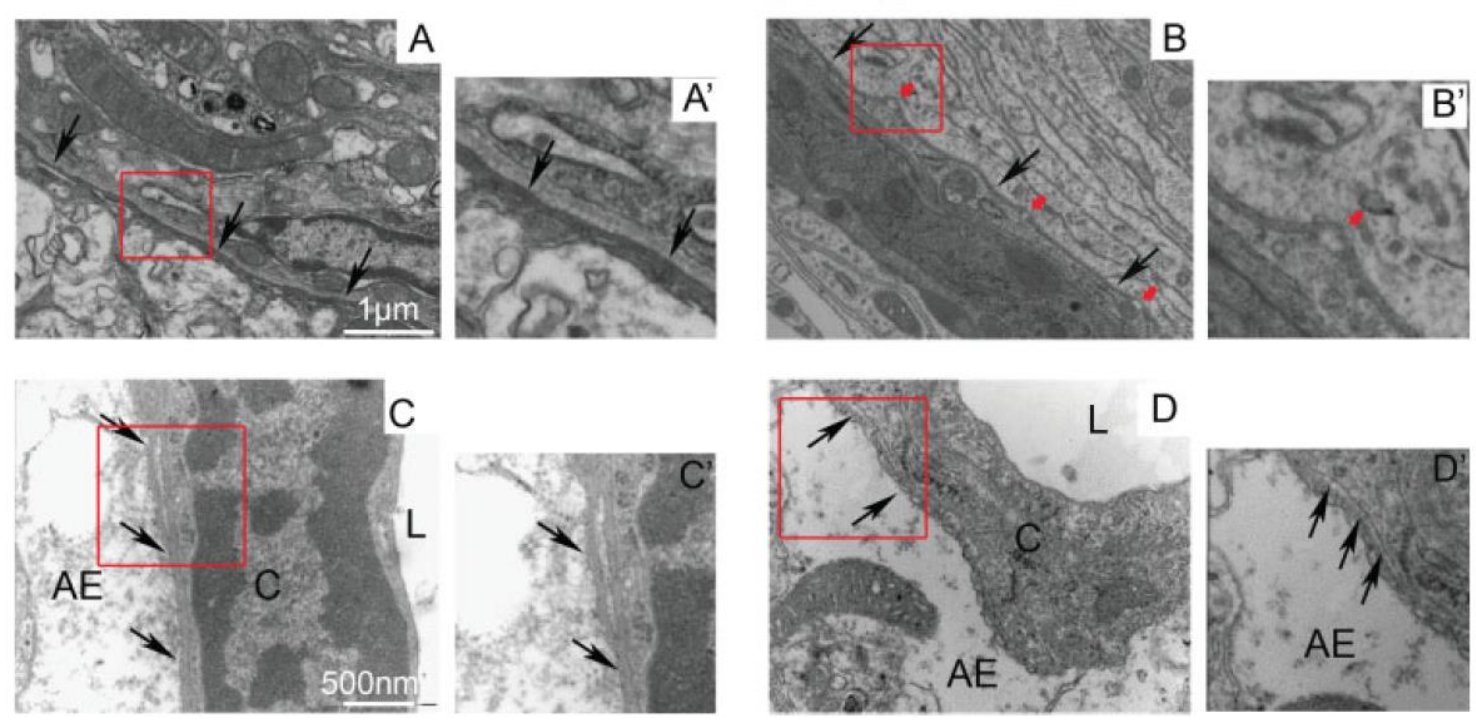

Figure 7 
WT
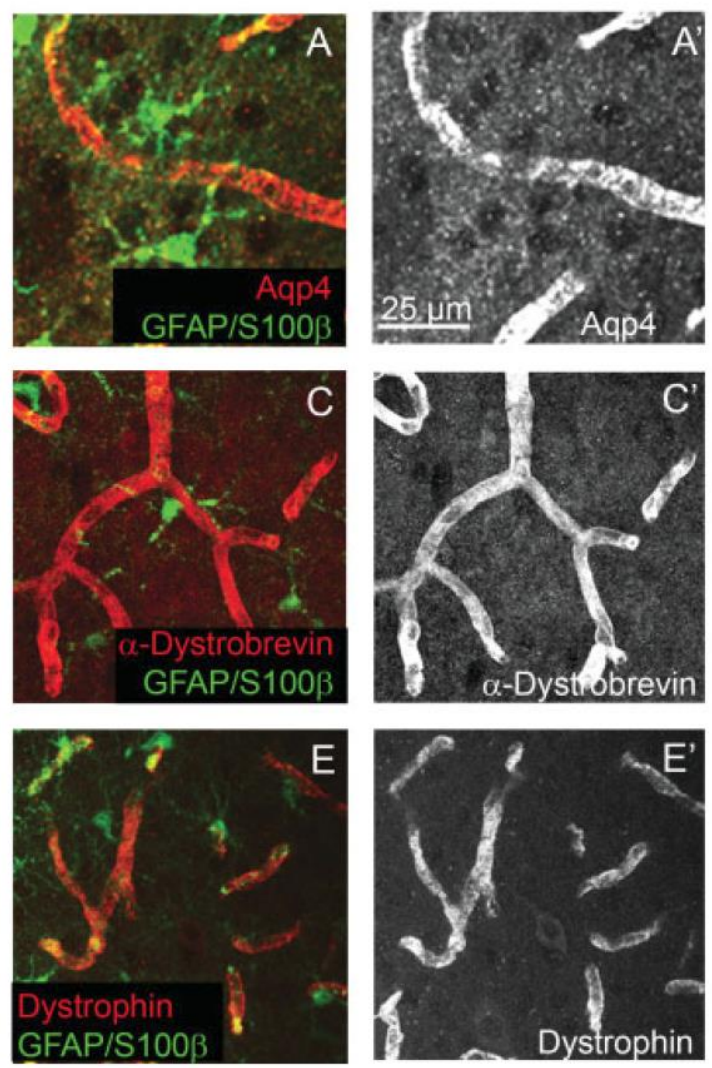

E

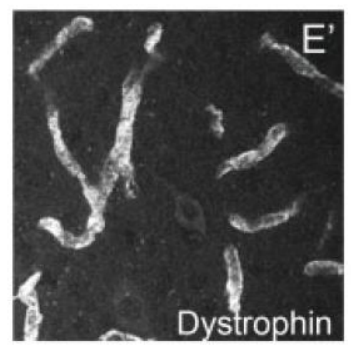

$\beta 1$-integrin -/-
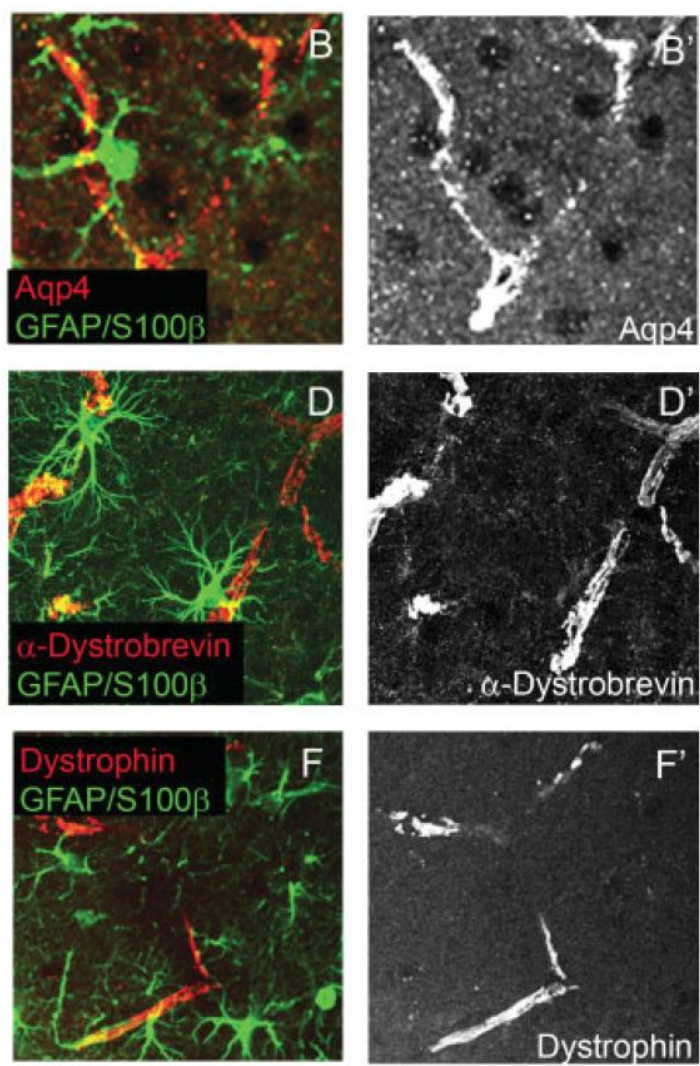

Figure 8 


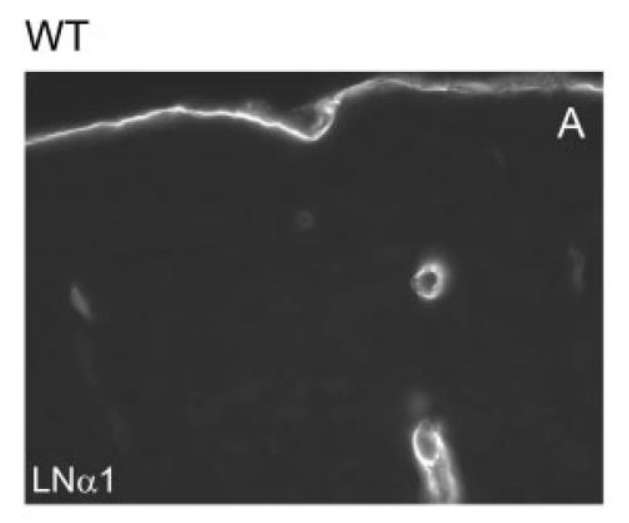

$\beta 1$-integrin -/-
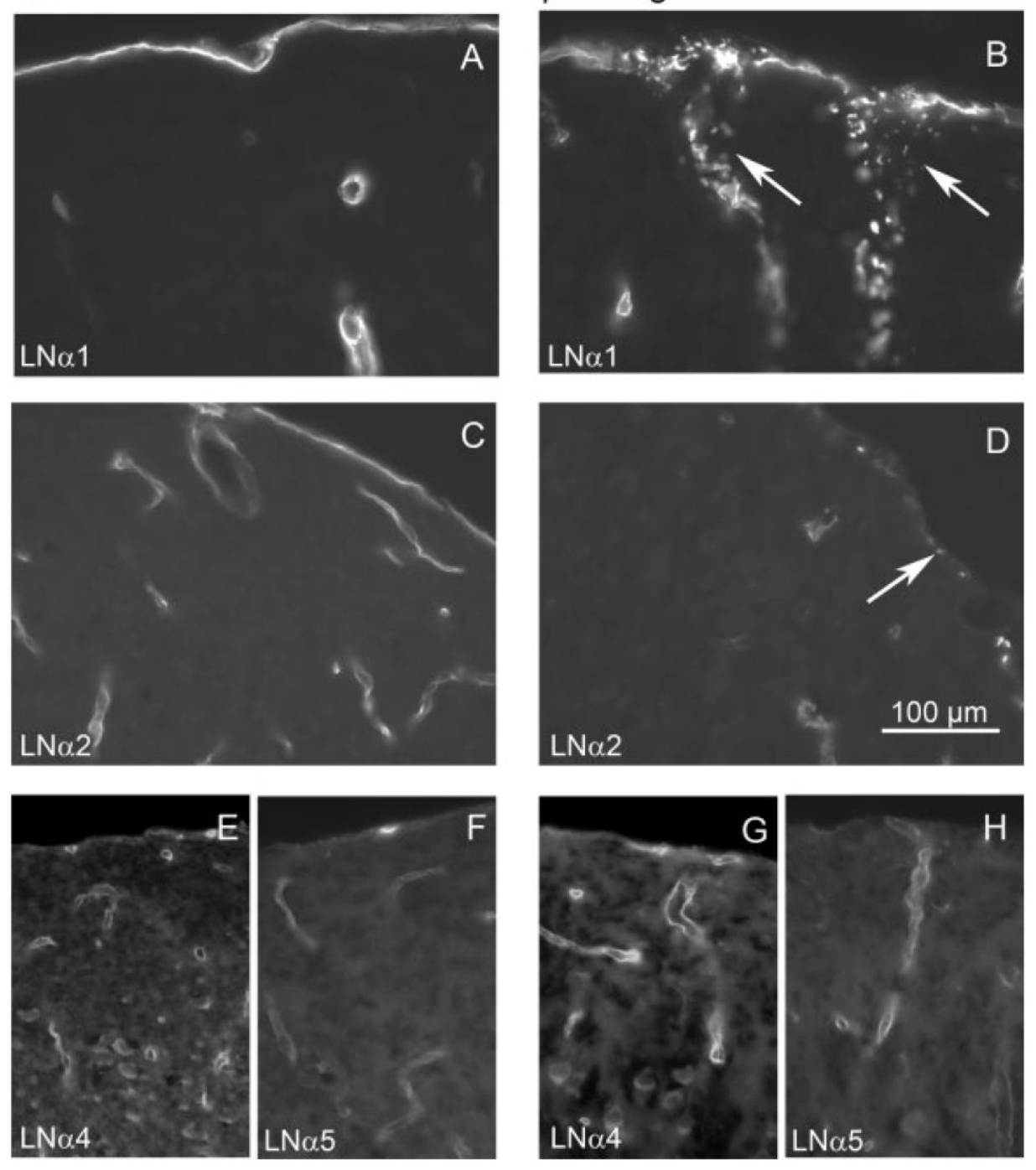

Figure 9 
b1 integrin WT
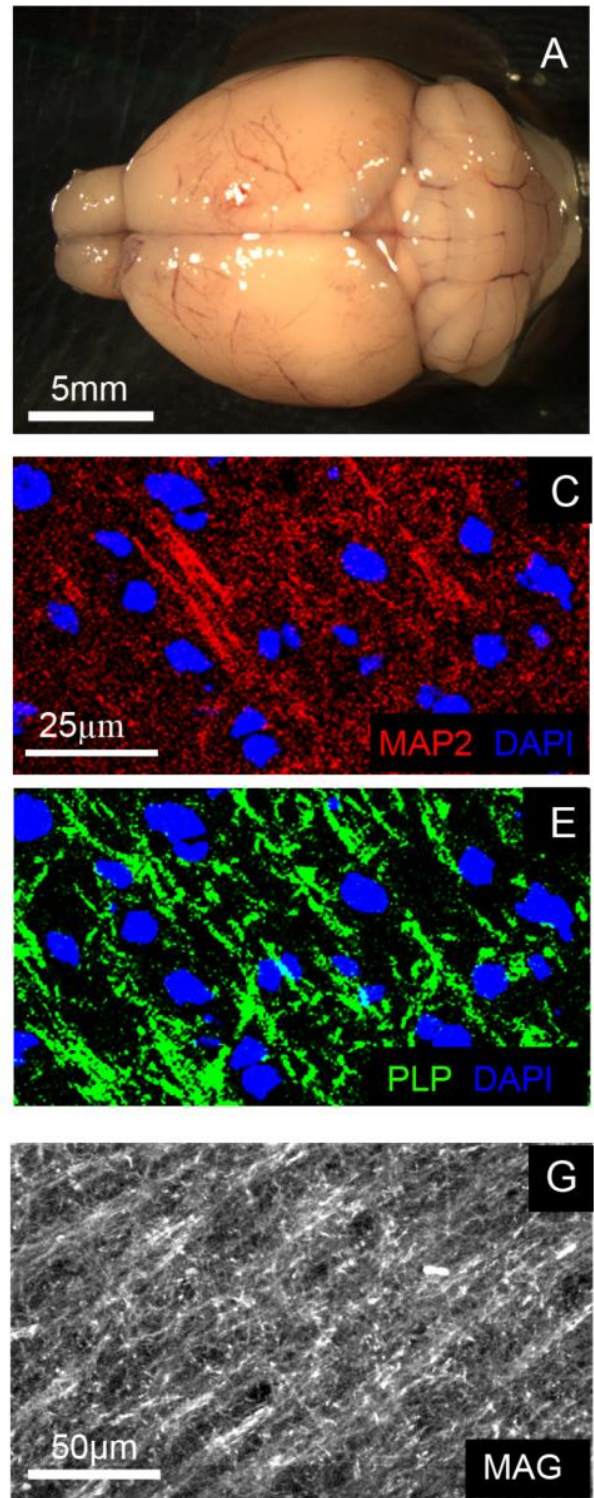

b1-integrin -/-
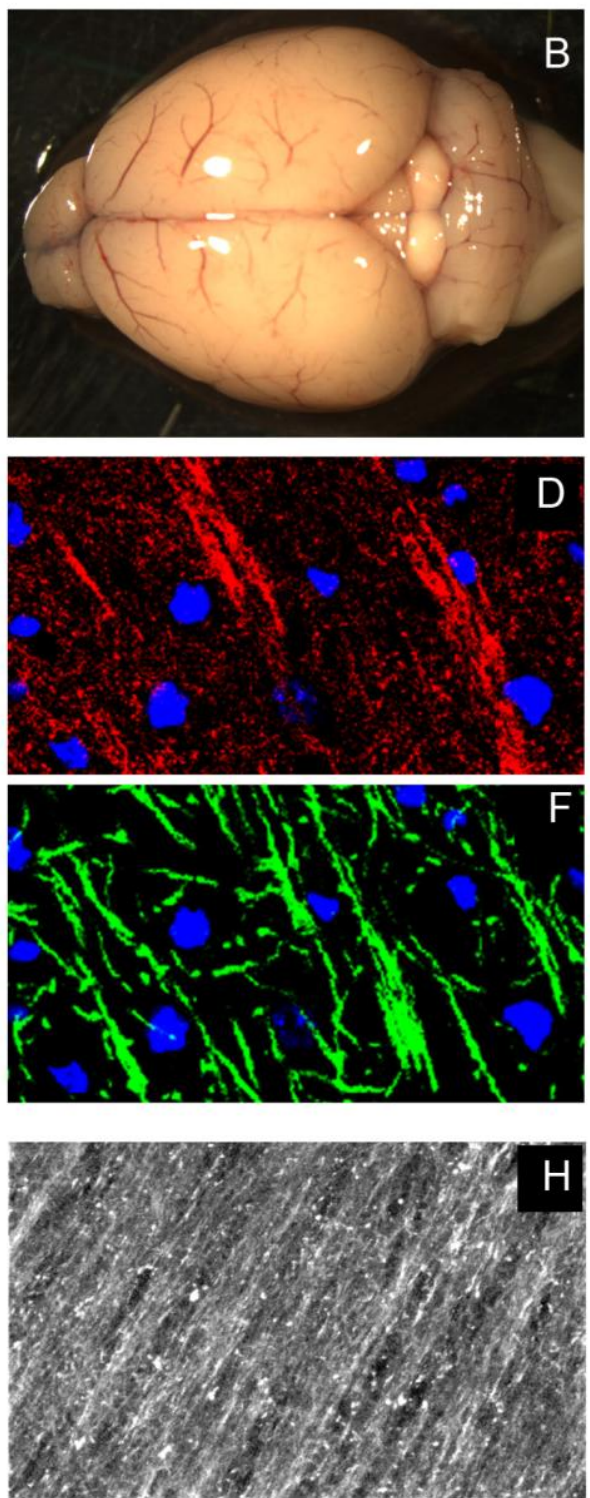

Supplemental figure 1 
b1 integrin WT
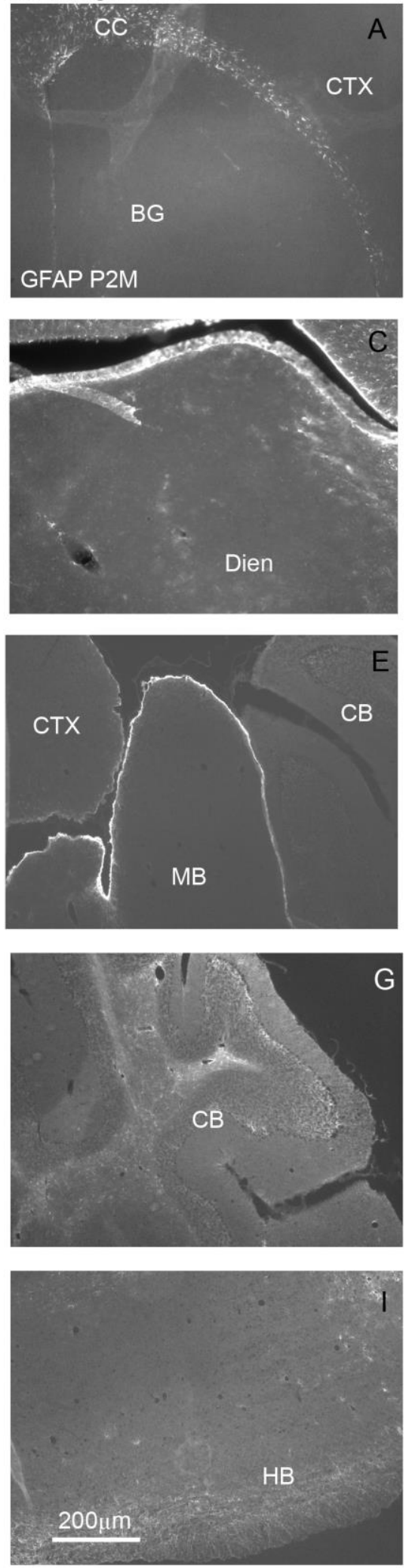

b1 integrin -/-
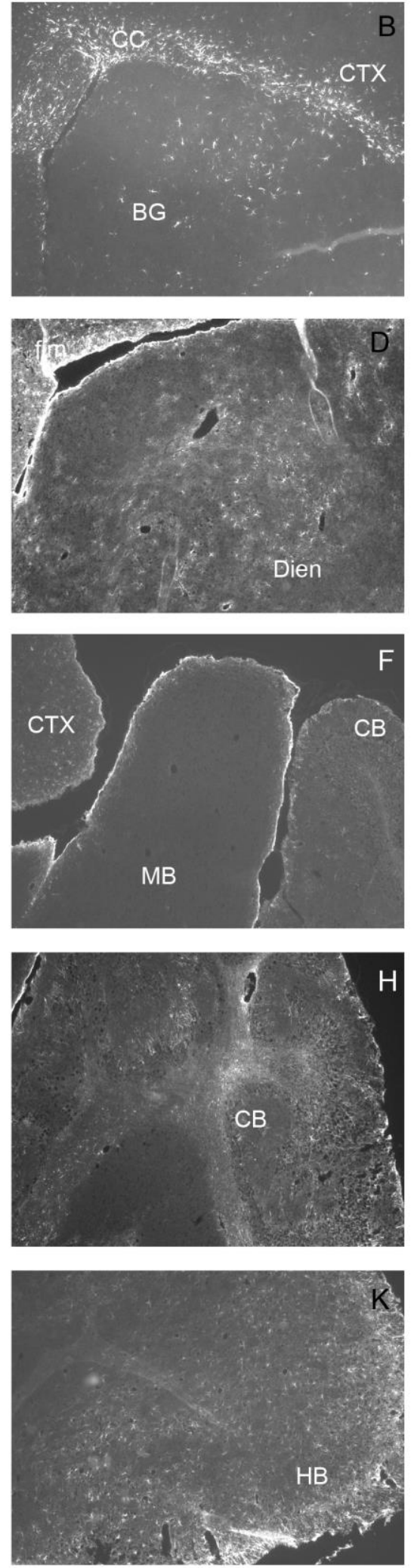

Supplemental figure 2 


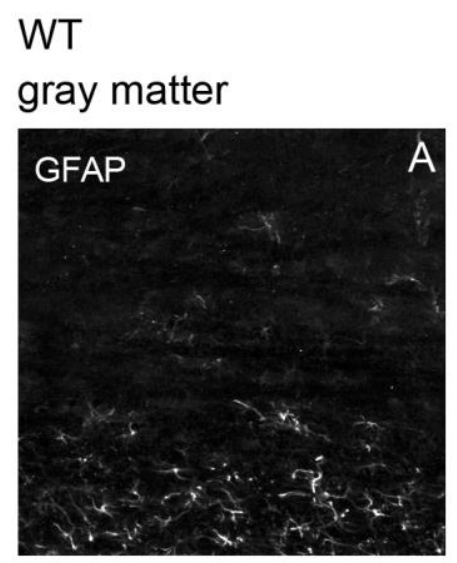

$\beta 1-/-$

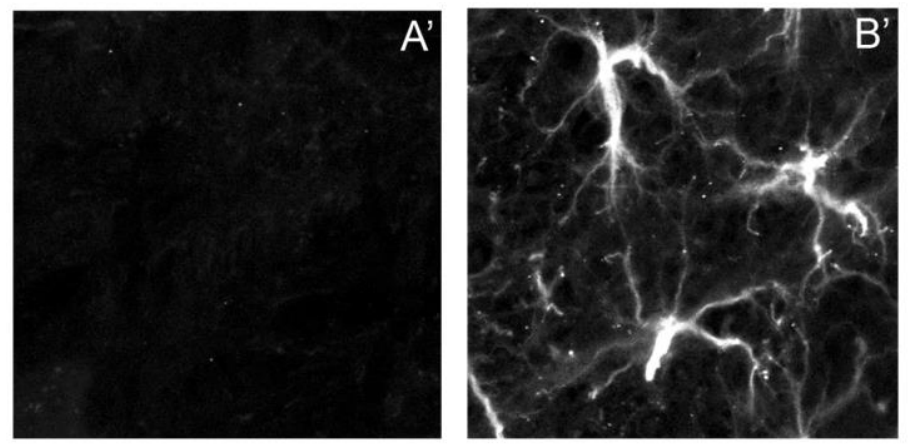

white matter

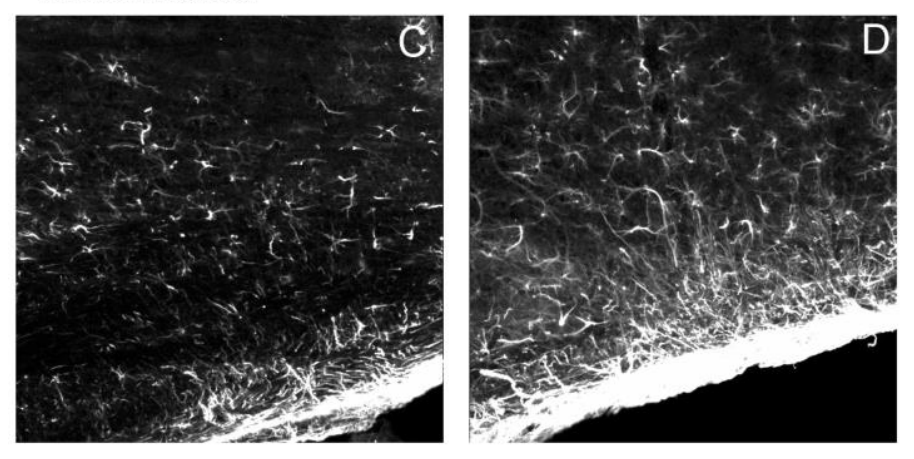

Supplemental figure 3 

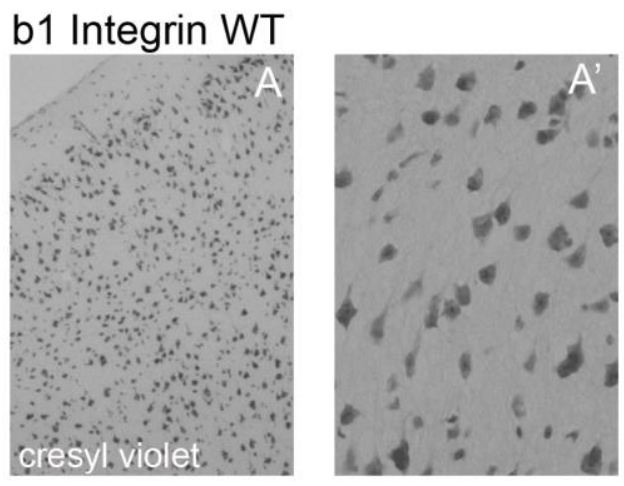

b1 Integrin -/-
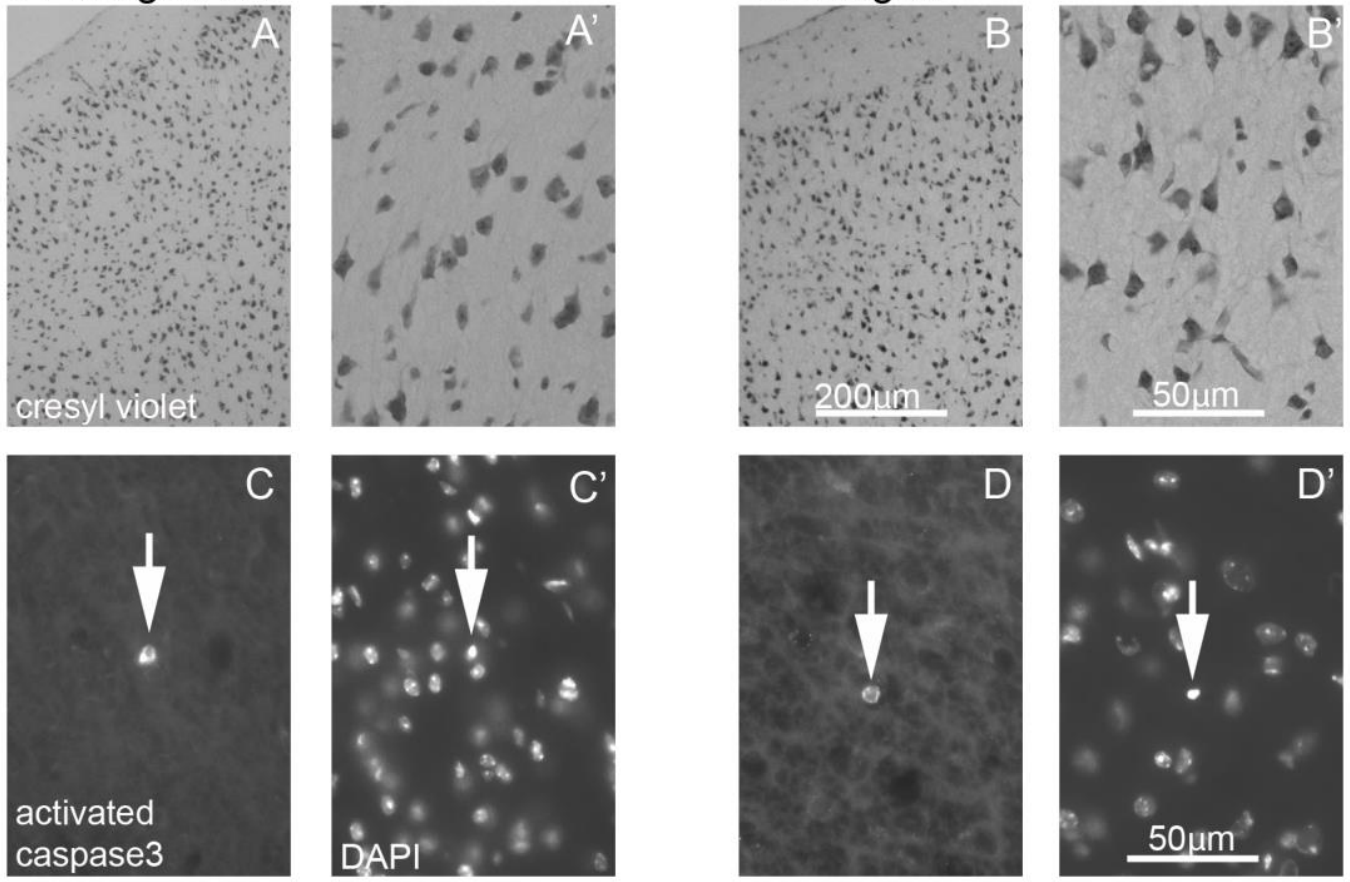

Supplemental figure 4 


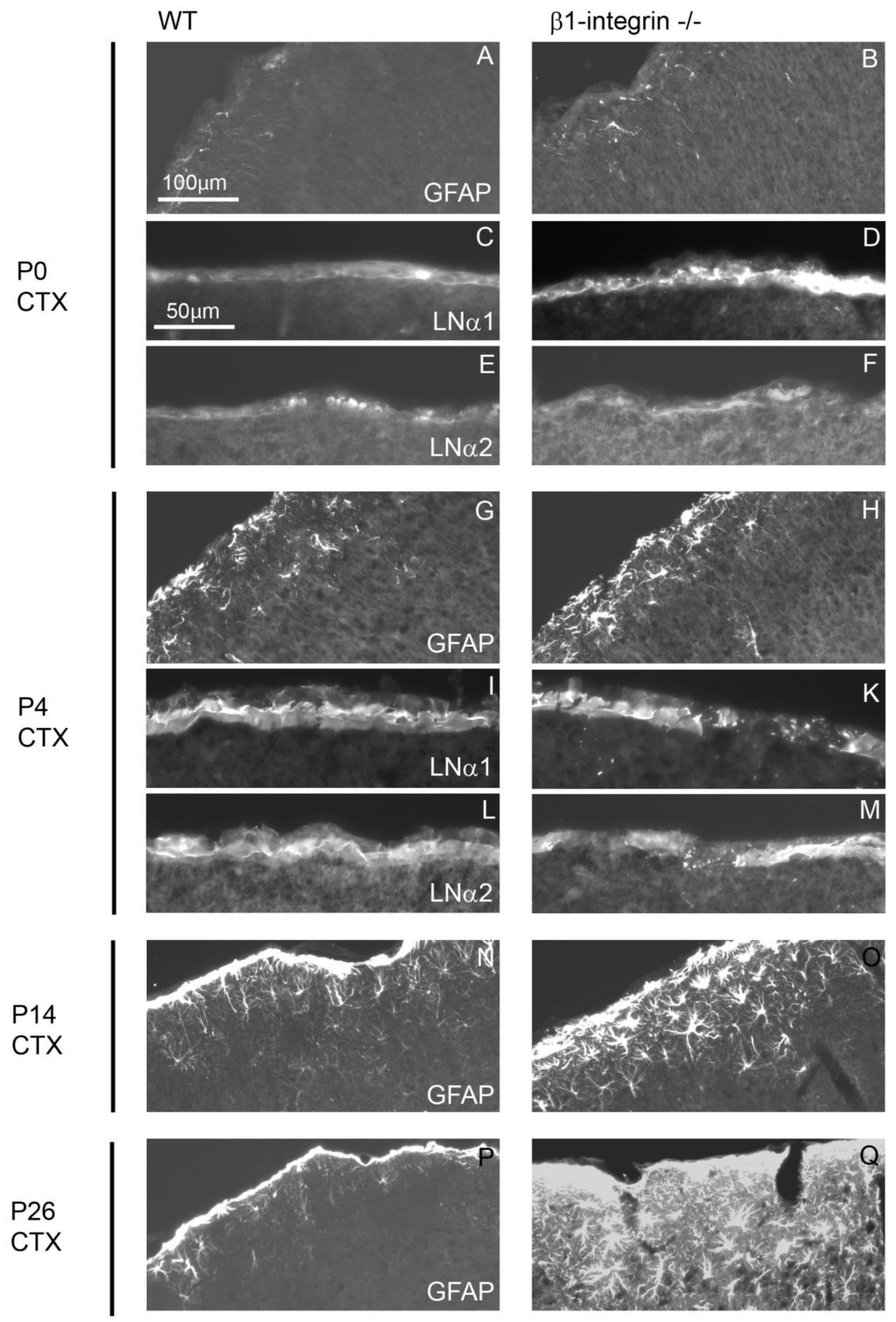

Supplemental figure 5 


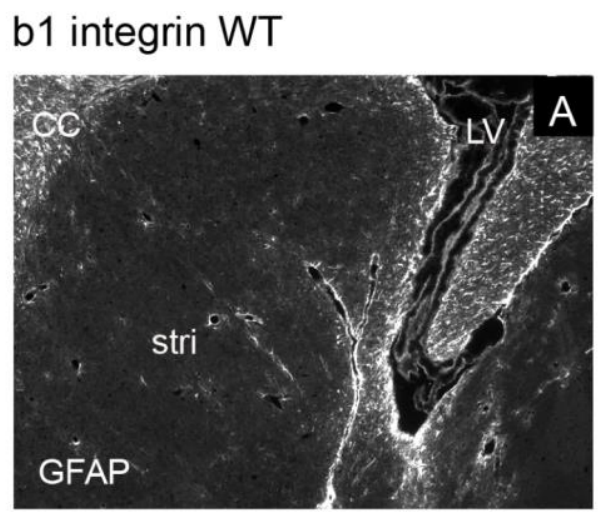

b1 integrin -/-
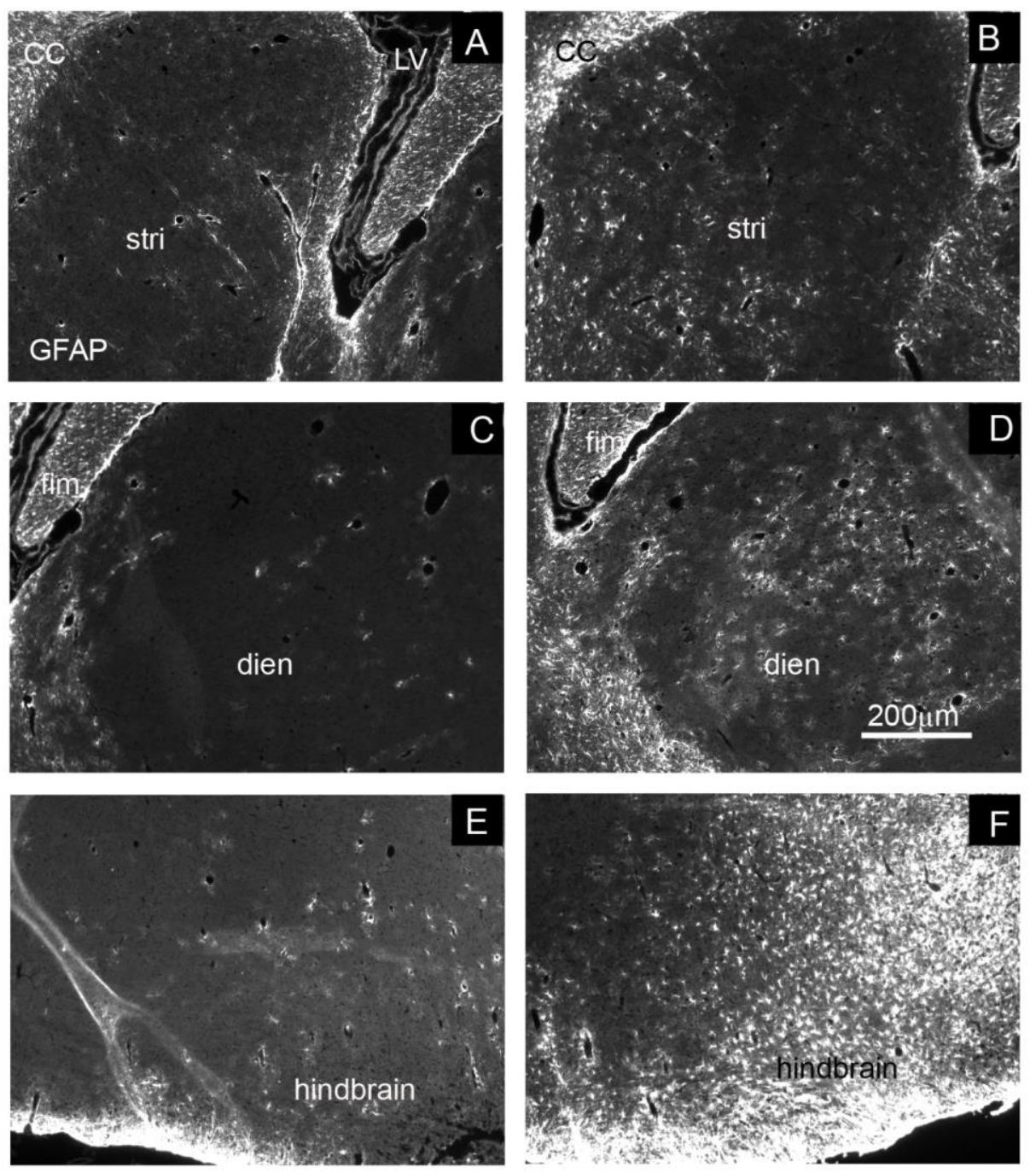

Supplemental figure 6 